\title{
A Wireless Head-mountable Device with Tapered Optical Fiber-coupled Laser Diode for Light Delivery in Deep Brain Regions
}

\author{
Mohamed S. Emara, Member, IEEE, Marco Pisanello, Leonardo Sileo, Massimo De Vittorio and \\ Ferruccio Pisanello
}

\begin{abstract}
Optogenetics sets new experimental paradigms that can reveal cell type-specific contributions on the neural basis of behavior. Since most of the available systems for this purpose are based on approaches that tether animals to a set of cables, recent research activities have been focused on minimizing external factors that can alter animal movements. Current wireless optogenetic systems are based on waveguide-coupled LED and implanted $\mu$ LEDs. However, each configuration separately suffers from significant limitations, such as low coupling efficiency, penetration depth and invasiveness of waveguide-coupled LED, and local heat generated by implanted $\mu$ LEDs. This work presents a novel wireless head-mountable stimulating system for a widevolume light delivery. The device couples the output of a semiconductor laser diode (LD) to a tapered optical fiber (TF) on a wireless platform. The LD-TF coupling was engineered by setting up far-field analysis, which allows a full exploitation of mode division demultiplexing properties of TFs. The output delivered light along the tapered segment is capable of stimulating structures of depths up to $\sim 2 \mathrm{~mm}$. TFs are tapered to a gradual taper angle $\left(\Psi \sim 2^{\circ}\right.$ to $\left.\Psi \sim 10^{\circ}\right)$ that ends with a sharp tip $(\sim 500 \mathrm{~nm})$ for smooth insertion and less invasiveness. Thus, the proposed system extends the capabilities of wireless optogenetic by offering a novel solution for wide volume light delivery in deep brain regions.
\end{abstract}

Index Terms-Deep brain stimulation, optogenetics, tapered optical fiber, semiconductor laser diode, wireless device.

Mohamed S. Emara and Massimo De Vittorio are with Istituto Italiano di Tecnologia (IIT), Center for Bio-Molecular Nanotechnologies, Via Barsanti snc, 73010 Arnesano (LE), Italy, and Dipartimento di Ingegneria dell'Innovazione, Università del Salento, Via per Monteroni, 7300 Lecce, Italy (email: mohamed.emara@iit.it, massimo.devittorio@iit.it. Marco Pisanello, Leonardo Sileo and Ferruccio Pisanello are with Istituto Italiano di Tecnologia (IIT), Center for Biomolecular Nanotechnologies, Via Barsanti snc, 73010 Arnesano (LE), Italy (email: ferruccio.pisanello@iit.it).

\section{INTRODUCTION}

$T^{\mathrm{Hin}}$ HE development of optogenetics [1] has offered neuroscientists a set of new tools to control neural activity by using visible light radiation. By genetic expression of light-gated ion channels and pumps, such as Channelrhodopsin2 (ChR2) and Halorhodopsin (Halo) [2], it is possible to stimulate or inhibit the generation of action potentials with high spatiotemporal resolution and cell-type specificity [3-5]. Since its first application in mammalian neurons [6], it has been clear that tissue absorption and scattering strongly influence (and limit) the spatial extension of light patterns that are used to trigger the electrical activity of neural cells [7]. For this reason, intense technology development has been devoted to improving light delivery into brain tissue [2, 8-10] by developing implantable micro lightemitting diodes ( $\mu$ LED) [11-18], silicon nitride or silicon dioxide waveguides [19, 20] and new generations of both polymeric and glass-based optical fibers [21-28]. However, most of these approaches tether the animal with electrical or optical connections to bench-top equipment, whereas most in vivo readout behavior experiments require to preserve the natural movements of the animal. Therefore, particular attention has been driven by the need of implementing wireless optogenetics stimulation with no (or very limited) constraints on animal movements.

The resulting wireless optogenetics stimulation technologies have adopted two main configurations: (i) fullyimplantable devices that are based on LEDs and $\mu$ LEDs [2934], and (ii) head-mountable devices, which mainly adopt one of the following configurations: LEDs [35-38], $\mu$ LEDs [12, 15, 39-43], waveguide-coupled LED [28, 44-49] or waveguidecoupled $\mu$ LED [50-52]. Both approaches depend exclusively on LEDs, although they suffer from significant limitations. The broad emission of LEDs [11] leads to a low coupling efficiency to optical waveguides [53], resulting in a small illuminated volume and consequently in a low number of stimulated cells. The low coupling efficiency of LEDs is commonly compensated by a relatively large-diameter waveguide, which increases the invasiveness of the implant. As an alternative to large-core fibers, the emission power of LEDs can be increased to overtake the activation threshold of excitatory and inhibitory opsins ( 1 $\mathrm{mW} / \mathrm{mm}^{2}$ and $\sim 7 \mathrm{~mW} / \mathrm{mm}^{2}$, respectively) $[54,55]$ over wider volumes. However, this choice for a wireless solution is critical, since the level of power consumption would increase, leading to employing batteries with higher capacity or limiting the running time. On the other side, $\mu$ LEDs are less invasive and can be implanted into deep brain areas such as the ventral tegmental area (VTA) [29], but when they are operated for long periods or at high powers to increase the stimulated volume, unavoidably increase local temperature of tissues [11, $15,56]$, which may lead to thermal artefacts and increasing the damaging rate to in-contact tissues $[54,57]$.

The approach we report here is designed specifically for targeting deep brain regions in freely-moving animals; it overcomes the light delivery limitation of LEDs on wireless platforms, by coupling the output of a semiconductor laser diode to low invasive tapered fibers (TF). By implementing farfield analysis, LD-TF coupler was engineered to exploit the mode-division demultiplexing properties of TFs to generate a gradual outcoupling of guided modes along the taper. The light 
emission length along the tapered segment can be tailored from $\sim 400 \mu \mathrm{m}$ to $\sim 3 \mathrm{~mm}$ by acting on the taper angle $\left(2^{\circ}<\Psi<10^{\circ}\right)$. This light emission length allows to stimulate the entire depth of functional structures in the mouse brain, such as the cerebral cortex, striatum and hippocampus. Our TFs were tapered to a sharp tip ( $\sim 500 \mathrm{~nm})$ for smooth insertion and less invasiveness, compared to previous systems (Fig1 (a)). The head-mountable device is powered by light-weight rechargeable batteries and triggered wirelessly for real-time control of neural activity by infrared (IR). Its light delivery capabilities, output optical properties, weight, size, and thermal behavior let us envision that this approach can represent an important complement to the currently available wireless systems for optogenetic stimulation.

\section{SYSTEM DESIGN}

The complete wireless optogenetic stimulation system consists of two modules: the TTL wireless transmitter, and head-mountable device, which receives the TTL signal and optically stimulate the brain tissues through the implanted TF. Fig1 (b) and (c) show the experimental model and block diagram of the proposed approach, respectively. The transmitter itself comprises a generator of a TTL trigger signal, which is subsequently transmitted by a single or group of IR LEDs (SFH4725S, OSRAM $\lambda \sim 950$, emission angle $45^{\circ}$ ) to cover large and complex experimental environments. As shown in Fig1 (b), the head-mountable device at angle $0^{\circ}$ with the emitter, can detect the signal successfully at a distance of $\sim 60$ $\mathrm{cm}$ from the emitter. A distribution of three IR LEDs is enough to cover a square area of $\sim 0.3 \mathrm{~m}^{2}$ from a height of $\sim 60 \mathrm{~cm}$, or a square area of $1.5 \mathrm{~m}^{2}$ from a height of $\sim 30 \mathrm{~cm}$. Fig1 (c) exhibits the flow of the signal from the transmitter until it reaches the implantable fiber on the head-mountable device. The head-mountable device ( $15 \times 13 \times 15$ (h) $\mathrm{mm} ; 3.8 \mathrm{~g})$ is divided into the headstage (3.3 $\mathrm{g}$ with batteries) and the implantable unit $(0.5 \mathrm{~g})$, which comprises the TF-coupled semiconductor LD. The implantable unit is attachable and detachable to and from the headstage by 2-pin receptacles.

The head-mountable device was designed to exploit the peculiar properties of TFs to obtain a wide volume light delivery with minimal invasiveness. To the best of our knowledge, all the waveguide-coupled wireless solutions in literature are based on LED and $\mu$ LED [28, 44, 46-48, 50, 58]. In our case, TFs require a precise control over the modal content injected into the fiber since their working principle is based on the gradual leakage of guided modes along the taper [22]. This can hardly be achieved by using LEDs, which are well-known of their low coupling efficiency with waveguides, and wide irradiated angles due to the Lambertian emission pattern (from $\sim 90^{\circ}$ to $120^{\circ}$ ) $[54,59]$. Laser Diodes (LDs) offers a more directional output. Here, the light injection system is based on OSRAM LD Q65111A0518, emitting at $\lambda \sim 450 \mathrm{~nm}$, with minimum and maximum divergence angles $\theta_{\perp} \times \theta_{/ /}: 4^{\circ} \mathrm{x} 18^{\circ}$ and $25^{\circ} \times 11^{\circ}$, respectively [60], which are matching well with the $\sim 23^{\circ}$ acceptance angle of 0.39 NA core/cladding 200/225 $\mu \mathrm{m}$ optical fibers.

The use of LDs instead of LEDs introduces some constraints on the design of a lightweight device. The LD must be supplied by a stable forward current (from anode to cathode) to avoid fluctuations in the LD output optical power. Furthermore, it is well-known that LD surface temperature increases during the operation and it needs to be stabilized at almost room temperature for assuring a constant light delivery power during on pulses.

The headstage was designed to emit pulses of light on sub-milliseconds. This was obtained by designing the headstage to use a low number of components, connected in series, to minimize the latency with respect to the received TTL signal. The rising and falling times of the emitted pulses by the headstage is less than $<20 \mu \mathrm{s}$. Fig1 (d) shows the emitted light pulses by the head-mountable device at TTL trigger signal of $200 \mathrm{~Hz}$ and $10 \%$ duty cycle (D) with a resulting pulse width of $500 \mu \mathrm{s}$.

These design motivations and considerations lead to a headstage consisting of a stimulation module (Fig2 (a)) and a power module (Fig2 (b)). The stimulation module is centered on a spike-free switching LD-switch (IC-HKB MSOP8-TP, iCHaus; $155 \mathrm{MHz} ; 1.5 \mathrm{~ns}$ forward current rise and fall time). It switches the LD on and off wirelessly, according to the received signal by the IR phototransistor (TEKT5400S-ASZ, Vishay; $37^{\circ}$ ). The output optical power of the LD is regulated by a surface mount $10 \mathrm{k} \Omega$ trimmer, which regulates the voltage on the "CI" pin of the LD switch. The applied voltage to the "CI" pin sets the fed forward current to the LD. The Schottky and Zener diodes are in parallel with the LD to protect it against reverse polarity connection, electrostatic discharge and overrated forward voltages. The surface temperature of the laser diode was stabilized by adding a heatsink. The system is powered by two $3.7 \mathrm{~V} / 50 \mathrm{mAh}$ lithium rechargeable batteries. The input voltage $6 \mathrm{~V}$ goes directly to the LD and dual-voltage regulator (Fig2 (b)). The dual-voltage regulator (ON Semiconductor, NCP5504DTRKG) regulates the input voltage to $5 \mathrm{~V}$ (the LD switch), and 3.3V (the trimmer). The Diode D1 (Bourns, CD0603-B0230) in parallel with the battery terminals protects the circuit against reverse polarity connection. The platform that electrically connects all the components and holds them mechanically is a thin $0.3 \mathrm{~mm}$ double-sided flexible PCB $14.0 \mathrm{~mm} \times 13.5 \mathrm{~mm}$ (Fig2 (c-d)). The flexible and thin PCB contributes to minimizing the headstage total weight $(0.8 \mathrm{~g}$ after hand soldering all the components, without batteries).

\section{COUPling TAPERED OPTICAL FIBER FOR WIDE VOLUME LIGHT DELIVERY}

Towards minimizing the size of the implantable unit, a buttcoupling between the TF and LD has been realized, as sketched in Fig3 (a). Considering the minimum $\sim 1.02 \mathrm{~mm}$ distance between the LD emission point and the TF input facet, LD emission is projected on a $\sim 0.07 \mathrm{~mm}^{2}$ elliptic surface, which overfills the $\sim 0.03 \mathrm{~mm}^{2}$ surface area of the fiber core (see launch conditions between the laser beam and fiber core in Fig3 (a)). The result of the LD beam divergence matches well with the $23^{\circ}$ acceptance angle of 0.39 NA and $\varnothing 200 \mu \mathrm{m}$ core fiber. This is an important aspect, since TFs emission properties are mostly based on the modal content of light guided into the fiber, which are strongly dependent on the input angle of light injected into the fiber. As already demonstrated in refs [21, 22, 25], injecting rays into the fiber facet with low input angles (low transversal component of the wave-vector $\mathrm{K}_{\mathrm{t}}$ ) results in out- 
coupled rays closer to the fiber tip, whereas injecting rays with higher input angles (high $\mathrm{K}_{\mathrm{t}}$ modes) leads to out-coupling further from the taper tip (see ray tracing schematics in Fig3 (b)). Therefore, to get the longest possible light emission length over the taper segment, the system must inject light into the TF with the highest possible angular range while preserving a highenough coupling efficiency at the same time.

To verify that the butt-coupling method allows injecting guided modes with a wide-enough range of $\mathrm{K}_{t}$ values, the far field system depicted in Fig4 (a) was used. A patch fiber was butt-coupled to the LD TO38 package, while the fiber output was detected by Lens L1 (focal length, f1=4.6 mm), generating a far field pattern of the light emitted by the optical fiber in its focal plane. Such pattern was then magnified by a factor $\sim 3.3$ and imaged over a sCMOS camera by lenses L2 (f2=30 mm) and L3 (f3=100 mm). In the resulting far-field images, $\mathrm{K}_{\mathrm{t}}$ is decomposed along the two-orthogonal-axis of the sensor chip in two components, namely $\mathrm{K}_{\mathrm{x}}$ and $\mathrm{K}_{\mathrm{y}}$. In particular, $\mathrm{K}_{\mathrm{t}}$ is related to the signal detected by the sensor chip at distance $r$ from its center by the following equation:

$$
r=\frac{F 1 F 3}{F 2} \tan \left(\sin ^{-1}\left(\frac{\lambda}{2 \pi} K_{t}\right)\right)
$$

Typical far-field patterns for different relative TF-LD positions are shown in Fig4 (b), with the correspondent decomposition on the $\mathrm{K}_{\mathrm{x}}$ axis and total emitted power ( $\mathrm{P}_{\text {Coupling }}$ ) displayed in Fig4 (c-d), respectively. For evaluating the achieved coupling position in respect to the outcoupled light emission length along the taper $(\mathrm{L})$, we collected fluorescence images, obtained by submerging a TF with $\Psi \sim 4^{\circ}$ into a droplet of PBS:fluorescein (see Fig5 (a)). The coupling position \#4 shows the widest $\mathrm{K}_{\mathrm{t}}$ interval and the longest emission from the taper ( $\mathrm{L} \sim 1.48 \mathrm{~mm})$. This result is almost equal to the maximum emission length $\mathrm{L} \sim 1.66 \mathrm{~mm}$ that was achieved by bench-top laser for the same TF. On the contrary, for coupling position \#5 (highest coupling efficiency) L 0.66 $\mathrm{mm}$ was obtained, due the narrower set of $K_{t}$ values injected into the waveguide. The repeatability of the coupling position was estimated by running multiple alignment sessions. On a total of $n=3$ independent sessions, a standard deviation of $\sigma_{L} \sim 0.10 \mathrm{~mm}$ over an average emission length of $\mathrm{L} \sim 1.34 \mathrm{~mm}$ was reported.

Total emitted power by the TF was tested by setting $\mathrm{LD}$ emitting power at $\mathrm{P}_{\mathrm{LD}} \sim 16 \mathrm{~mW}$. Position \#4 results in a lower coupling efficiency ( $\sim 25 \%)$ in comparison with position \#5 ( 44\%) (Fig4 (d)). However, the power density generated by the taper at coupling position \#4 is $\sim 10 \mathrm{~mW} / \mathrm{mm}^{2}$, which is well above the $\sim 1 \mathrm{~mW} / \mathrm{mm}^{2}$ for activating ChR2 [6]. The related spatial distribution $(\mathrm{P})$ is shown in Fig5 (b) for a TF at the coupling position \#4. $\mathrm{P}$ was calculated by a Matlab script that integrates the density profile over the tapered surface for a given total output power. The calculations were done under the assumption of rotational symmetry around the taper axis, and considering the proportionality between the grayscale values registered by the $\mathrm{sCMOS}$ sensor and $\mathrm{P}$ (more details on these calculations are given in the Appendix).

As further validation that this method allows obtaining a functional coupling between TF and LD, and that it preserves the basic operational features of TFs [25], we tested TFs with taper angles ranging from $\Psi \sim 2^{\circ}$ to $\Psi \sim 10^{\circ}$. As shown by the data displayed in Fig5 (c), the emission length (L) can be tailored from a few hundred of micrometres to $\sim 3 \mathrm{~mm}$ by modifying the taper angle at the same coupling position \#4 for each case. The output power distribution for a TF with a very low $\Psi$ is also shown in the Appendix (Fig.S2).

\section{Time Stability OF LASER DiODE EMISSION}

It is well known that the stability of the output optical power $\left(\mathrm{P}_{\mathrm{LD}}\right)$ of a semiconductor $\mathrm{LD}$ can be affected by a noisy forward current or by non-efficient heat dissipation, which lowers the LD forward voltage and directly decreases the emitted power. This phenomenon is shown in Fig6 (a), the T038 LD (without a heatsink) is supplied with a stable forwardcurrent, according to TTL trigger signal with frequency/dutycycle $100 \mathrm{mHz} / 50 \%$ at $\mathrm{P}_{\mathrm{LD}} \sim 20 \mathrm{~mW}$. This signal was chosen as a "heavy load case reference", since it sets the LD 5s-on and 5soff, while most optogenetics stimulation protocols are on the tens of milliseconds range with small duty cycles [8]. For $\sim 3$ minutes of constant stimulation, the LD generated 22 5s-pulses; the $\mathrm{LD}$ surface temperature $\left(\mathrm{T}_{\mathrm{LD}}\right)$ reached $48^{\circ} \mathrm{C}$ at the end of this operational cycle. Due to this rapid increase of the LD surface temperature, the $\mathrm{P}_{\mathrm{LD}}$ decayed $\sim 50 \%$. To examine this phenomenon, we measured power losses (PL\%) for different $\mathrm{P}_{\mathrm{LD}}$ settings for the same TTL trigger signal $(100 \mathrm{mHz} / 50 \% / 22-$ pulses). As shown in Fig6 (b), low levels of $\mathrm{P}_{\mathrm{LD}}$ induce a higher power decay, since the temperature increase can induce subthreshold operation as illustrated in the datasheet [60]. For further examination of the thermal behavior of the LD, in Fig6 (c-d) we recorded the surface temperature of the LD ( $\left.\mathrm{T}_{\mathrm{LD}}\right)$ package and the PL\% at two different power levels $\mathrm{P}_{\mathrm{LD}} \sim 20 \mathrm{~mW}$ and $\mathrm{P}_{\mathrm{LD}} \sim 40 \mathrm{~mW}$ along 5 different stimulation protocols commonly used for in vivo stimulation [15, 31, 61-63] (details of the protocols are given in the caption of Fig6). This feature prevents using the LD without the addition of a heatsink.

We worked on stabilizing the $\mathrm{P}_{\mathrm{LD}}$ by increasing the heat-dissipating surface, and therefore stabilize the power level and surface temperature. We fixed an aluminium ring on the base of the LD package (Fig6 (e2)), and we used a metallic ferrule for connectorizing the TF (Fig6 (e3)). All components were secured by the thermal epoxy (TBS20S, Electrolube) for better heat dissipation (Fig6 (e4)). Those added parts increased the surface area of the LD package by three times, subsequently, the heat dissipation enhanced as shown in Fig6 $(\mathbf{f}, \mathbf{g}, \mathbf{h}, \mathbf{i})$ in respect to the collected data of the bare LD in Fig6 (a, b, c, d). For the $100 \mathrm{mHz} / 50 \% / 22$-pulses TTL protocol, for $\mathrm{P}_{\mathrm{LD}} \sim 20 \mathrm{~mW}$ a power loss of $\sim 9 \%$ was recorded (Fig6 (f)), which drops to $\sim 0 \%$ for $\mathrm{P}_{\mathrm{LD}} \sim 40 \mathrm{~mW}$ (Fig6 (g)). Similar improvements were obtained for the stimulation protocols used in refs [15, 31, 6163] (Fig6 (i)), for which all tests at $P_{L D} \sim 40 \mathrm{~mW}$ resulted in no power loss, while $\mathrm{P}_{\mathrm{LD}} \sim 20 \mathrm{~mW}$ induces power losses well below $10 \%$ in all cases.

\section{POWER CONSUMPTION}

Typical power density used for in vivo optogenetic experiments ranges from 1 to $10 \mathrm{~mW} / \mathrm{mm}^{2}$ [8, 64]. Fig7 (a) shows the total current consumption of the head-mountable device at different applied voltages to the "CI" pin- the LD forward current control. At $\mathrm{V}_{\mathrm{Cl}}=1.58 \mathrm{~V}$, the coupler output 
optical power $\left(\mathrm{P}_{\mathrm{TF}}\right)$ is $4 \mathrm{~mW}$ (e.g. intensity $\sim 12.5 \mathrm{~mW} / \mathrm{mm}^{2}$ along a $\Psi \sim 4^{\circ} \mathrm{TF}$ ), and the headstage total current consumption is $45 \mathrm{~mA}$. The two main factors that control the total energy consumptions and therefore the battery running-time are the emitted $\mathrm{P}_{\mathrm{LD}}$ and duty cycle of the stimulus TTL signal. Fig7 (b) shows the energy consumption at different optical power densities: at the end of 3 minutes of constant stimulation of pulses with a duty cycle of $50 \%$, total energy consumption of $\sim 25 \mathrm{~J}$ was registered.

Since the commonly used optogenetic stimulation protocols rely on short pulses $[8,35,37]$, the maximum pulsed discharge current is an essential factor for setting the criteria for choosing the right powering batteries. Considering the power requirements of the head-mountable device, the system is supplied by two $3.7 \mathrm{~V} / 50 \mathrm{mAh}(5 \times 12 \times 15 \mathrm{~mm})$ lithium polymer rechargeable batteries (GM051215, PowerStream) in series. These batteries are characterized by low weight $(\sim 1 \mathrm{~g}$ each), reasonable capacity ( $\sim 4$ hours of continuous operation at $\mathrm{D}$ $25 \%$ \& pulse intensity of $\sim 10 \mathrm{~mW} / \mathrm{mm}^{2}$ ), and a high discharge current, 1C (discharge rate). Fig7 (c) shows the emitted optical power of the head-mountable device when it is operated continuously and without intervals at three typical optogenetic TTL trigger signals; the data were collected while the device was powered by the previously mentioned batteries. A slight decrease in the total output $(\sim<0.4 \mathrm{~mW})$ at the end of the operational cycle along the three cases was observed due to the minor increase of the LD's temperature during the operation and discharging the battery at a load $(45 \mathrm{~mA})$ almost equal to the maximum discharging current $(50 \mathrm{~mA})$. Pictures of the whole device are shown in Fig8. The headstage total weight is $3.8 \mathrm{~g}$ (see Table I), and the dimensions are $15 \times 13 \times 15$ (h) $\mathrm{mm}^{3}$, including batteries.

\section{DISCUSSION}

We present a wireless head-mountable device that exploits the optical properties of TFs to obtain wide-volume light delivery in freely-moving animals. The miniaturized device $\left(15 \times 13 \times 15\right.$ (h) $\mathrm{mm}^{3} ; 3.8 \mathrm{~g}$ with batteries) is triggered wirelessly by $\lambda \sim 950 \mathrm{~nm}$ infrared LED and powered by two rechargeable batteries in series. The head-mountable device consists of the headstage (composed by stimulation and power modules) and the implantable unit for light delivery. The light delivery is based on $0.39 \mathrm{NA}$ TF $(\varnothing 200 \mu \mathrm{m}$ core) coupled to a $\lambda \sim 450 \mathrm{~nm}$ semiconductor $\mathrm{LD}$, a unique combination that achieves a wide-volume light delivery and reduced invasiveness. The fiber outer diameter $(\mathrm{d}=\varnothing 225 \mu \mathrm{m})$ was tapered to $\sim 500 \mathrm{~nm}$ tip that guarantees a smooth insertion into brain tissues and reduction of the implant cross-section to a sharp tip. The taper emission length can be tailored from $\sim 400 \mu \mathrm{m}$ to $\sim 3 \mathrm{~mm}$ by changing the taper angle $\left(2^{\circ}<\Psi<10^{\circ}\right)$. The implanted TF is connectorized to a ferrule for a butt coupling with the LD. The length of the fiber that emerges out of the ferrule cannot be shorter than the taper length $(l)$, with $l=d /(2 * \tan (\Psi / 2))$. This is due to the fact that the glue used to fix the fiber into the ferrule would act as a "cladding", influencing modal configuration into the fiber and unavoidably modifying the light delivery properties of TFs. The metallic ferrule that is connectorized to the TF has mainly three functions: (i) the metallic surface of the ferrule, which is in a direct contact with the laser diode cane partially participates with stabilizing the LD's surface temperature, (ii) the ferrule makes the handling of the tapered fiber for the alignment process easier and more secure, and (iii) ferrule length here works as a bend relief for a cable; it prevents the bending of the fiber near the coupling point, which would induce modal mixing. The system emits stimulation pulses with rising and falling time $<20 \mu$ s with a complete control of the LD thermal behavior for TTL pulses up to $5 \mathrm{~s}$. The outcoupled power along the tapered segment can be controlled by both, manually by the $10 \mathrm{k} \Omega$ trimmer or the transmitted duty cycle. This latter possibility will mostly depend on the time response of the used opsin. The main characteristics of the system have been summarized in Table II.

To the best of our knowledge, the proposed headmountable device is the first to be specifically designed for wide-volume wireless light delivery, by exploiting the optical properties of TFs. LEDs and $\mu$ LEDs are the first and only solution, so far, for coupling light into implantable waveguides on wireless platforms [28, 44-48]. However, LDs offers more directional optical output in comparison to LEDs, resulting in a better coupling efficiency with TFs and full exploitation of their mode division demultiplexing properties. By using optical farfield analysis, the butt coupling between the LD and TF was optimized for obtaining the longest possible emission along the taper, while preserving a high-enough power density for ChR2 stimulation $\left(10 \mathrm{~mW} / \mathrm{mm}^{2}\right)$. In the condition of the longest possible emission along the taper segment, the coupling efficiency was found to be $25 \%$. Although this is not the maximum achievable coupling efficiency (which is $44 \%$, see Fig4 (d)), it allows overtaking opsins stimulation thresholds and it is considerably higher than the typical coupling efficiency $\sim 1 \%$ of LEDs with flat-cleaved fibers ( $\varnothing 200 \underline{\underline{m}}$ m core) [7]. In the wireless CerebraLux system [46], for instance, the coupling efficiency of the LED-coupled to $0.63 \mathrm{NA}$ flat optical fiber with double size core ( $\varnothing 450 \mu \mathrm{m}$ core) is only $10.2 \%$.

Another important advantage with respect to LEDs, LDs are more efficient in energy conversion [65]. By employing two $3.7 \mathrm{~V} / 50 \mathrm{mAh}$ batteries $(\sim 1 \mathrm{~g}$ each), the headstage can generate power density levels up to $\sim 10$ $\mathrm{mW} / \mathrm{mm}^{2}$ (see Fig5 (b)) with full emission length that can be tailored from $\sim 0.7$ to $3.4 \mathrm{~mm}$ (see Fig5 (c)). In comparison with the operational time of other systems, the programmable LED stimulator presented in ref [37] is composed by a headmountable device $(2.4 \mathrm{~g})$ powered by single $3.7 \mathrm{~V} / 10 \mathrm{mAh}$ battery $(0.52 \mathrm{~g})$ that can run the system for 67 minutes at TTL stimulation parameters $(50 \mathrm{~ms}$ pulses at $10 \mathrm{~Hz}$ for $2 \mathrm{~s}$ duration at $5 \mathrm{~s}$ intervals), and at power intensity $6.07 \mathrm{~mW} / \mathrm{mm}^{2}$ with LED $(1.6 \times 0.8 \times 0.68 \mathrm{~mm})$. The running time of the that system can be increased to $\sim 2 \mathrm{~h}$ by using a larger battery $20 \mathrm{mAh}(1.39 \mathrm{~g})$ that will increase the total mass of the head-mountable device to $3.27 \mathrm{~g}$ instead of $2.4 \mathrm{~g}$. The system we propose in this work can emit pulses at the same TTL stimulation parameters with a $1.65 \mathrm{x}$ higher intensity $\left(10 \mathrm{~mW} / \mathrm{mm}^{2}\right)$ with a longer illuminated segment $\sim 2 \mathrm{~mm}$ and running time of $\sim 7 \mathrm{~h}$, in a comparable mass $(3.27 \mathrm{~g} \approx 3.8 \mathrm{~g})$. This means that the proposed system is fit to run optogenetics stimulation experiments for reasonable durations before the need to be recharged. The batteries can be 
recharged on board, and by the connecting receptacles, the headstage is detachable from the implantable part.

\section{A. In comparison with flat cleaved optical fibers-coupled} LED

Waveguide-coupled LED is an interesting option for targeting deeper layers. The deep-brain stimulator presented in ref [48], for instance, is based on optical fiber-coupled LED. The system is powered by two solid-state batteries $(50 \mu \mathrm{Ah})$; by calculation, the batteries can run the system for one hour of continuous operation at $50 \% \mathrm{D}$ and $27 \mathrm{~mW} / \mathrm{mm}^{2}$ of irradiance out of the fiber facet (current consumption $21.01 \mathrm{~mA}$ ). On the other side, our system with a flat fiber can supply 44.5 $\mathrm{mW} / \mathrm{mm}^{2}$ (1.6x more) out of the fiber facet at almost the same current consumption level ( $25 \mathrm{~mA})$ for four hours of continuous operation ( $4 \mathrm{x}$ more) at $50 \% \mathrm{D}$. As a further comparison, the head-mountable $(4.9 \mathrm{~g})$ device for optical stimulation (flat optical fiber-coupled (core: $\emptyset 200 \mu \mathrm{m}$ ) LED) and neural recording proposed in ref [47], which is powered by a single $3.7 \mathrm{~V} / 100 \mathrm{mAh}$ battery $(2.1 \mathrm{~g}, 70$ minutes at $10 \% \mathrm{D}, 150 \mathrm{~mA}$ stimulation current for $\left.70 \mathrm{~mW} / \mathrm{mm}^{2}(2.19 \mathrm{~mW})\right)$. If the same flat fiber $(200 \mu \mathrm{m})$ is connected to our LD-based system the output power out of the fiber tip will be $225 \mathrm{~mW} / \mathrm{mm}^{2}(7 \mathrm{~mW}$, $3.2 \mathrm{x}$ more) at total current consumption of $45 \mathrm{~mA}(6.7 \mathrm{x}$ less), and at $10 \% \mathrm{D}$ the system can run continuously for $\sim 10 \mathrm{~h}(8.5 \mathrm{x}$ more). Moreover, we are utilizing the photonic properties of $\mathrm{TF}$, the illuminated area of the TF is larger than the illuminated area of the flat fiber $[10,21,25]$. Besides, the penetration depth of the TFs is deeper than the one of flat fibers so that high power transmission to overcome absorption and scattering factors can be avoided as described in our previous work [25]. This let us envision that our wireless device is more suitable for targeting deep brain regions than previous devices that are based on flat fiber-coupled LED [48], and can be considered as the second generation of wireless deep brain stimulation tools. The solution proposed here brought the capabilities of TF widevolume light delivery on a self-consistent wireless platform that is comparable in size and weight with the other systems (see the comparison in Table III).

\section{B. In comparison with $\mu L E D$ s shank}

$\mu$ LEDs shanks are another strong alternative for light delivery that has been utilized on a wireless platform [15, 32, $33,39-41,66]$. It is a versatile option that can be presented in different topologies with low Young's modulus for matching the mechanical properties of brain tissues. The number of $\mu$ LEDs on the implantable shank can be increased or decreased according to the design with the desired pitch. To our knowledge, the presented $\mu$ LED shanks on wireless platforms carry from 1 to $4 \mu \mathrm{LEDs}$ for localized light delivery with overall shank width of 250-500 $\mu \mathrm{m}$ and maximum full emission length not longer than $\sim 880 \mu \mathrm{m}$, by activating all the emitters simultaneously (see the comparison in Table IV). Beside the complexity of fabrication, the main challenge that implanted $\mu$ LEDs shanks face is the management of the thermal behaviour. Electronics in direct contact with tissues increase the local temperature, in particular when long stimulation pulses are needed $[11,15,56]$. Even $1-2^{\circ} \mathrm{C}$ temperature increase may cause tissue lesioning and adverse behavior $[11,57,67,68]$. In our case here, TFs avoid the direct contact of electronics with tissues, reduce the invasiveness factor in comparison with other approaches by tapering the outer diameter $(\varnothing 225)$ of optical fibers to a sharp tip $\sim 500 \mathrm{~nm}$ (see probe thickness and width on Table IV, and Table V), and have a longer light emission length $\sim 2 \mathrm{~mm}$ around $360^{\circ}$ (see Fig5 (c) and Table IV). $\mu$ LED shanks in wireless applications are designed for localized light delivery, that is directly reflected in small illuminated volumes and directly a lower power demand than wide-volume light delivery systems (the proposal of this work). Consequently, $\mu$ LED shanks can be powered by RF scavenging solutions, which contributes mainly in miniaturizing the total size, or by small batteries with low capacity (8 mAh) [39].

\section{Wireless optogenetic powering methods}

Powering methods for wireless and wearable applications, in general, is nearly among the most challenging aspects that face implantable free movement devices. We have summarized the main powering methods and wireless data transfer approaches for wireless optogenetic devices as well as for electrophysiological neural stimulation and recording in Table V: photovoltaics [41], wireless power transfer (WPT) [15, 29-34, 36, 44, 49, 50, 69], and batteries [28, 37-40, 45-47, $58,70,71]$. WPT [72] is an inevitable approach for fullyimplantable systems [29-34], which can be covered by a polydimethylsiloxane (PDMS) layer for full immersion. When WPT is applied to head-mountable devices, it is often accompanied by a supercapacitor for buffering, energy storage and stable powering [15, 36, 44, 50, 69]. WPT works on miniaturizing the implant whether it is near field magnetic resonant coupling (1-2 MHz to $13.56 \mathrm{MHz}$ ) [73] or far-field energy transfer $(420 \mathrm{MHz}$ to $2.4 \mathrm{GHz})[74,75]$. For example, the wireless optofluidic system $\left(15 \times 15 \times 7 \mathrm{~mm}^{3}\right)$ weights $\sim 1.8$ $\mathrm{g}$ when powered by batteries [39]; the size and weight of the system goes significantly down until $125 \mathrm{~mm}^{3}$ and $220 \mathrm{mg}$ once the system is powered by RF complex antenna setup [33]. However, the operational distance gets down to $10 \mathrm{~cm}$ instead of $3 \mathrm{~m}$ previously. This is one of the constraints that faces WPT, the low range. The other form of the WPT is the inductive platforms that wirelessly transmit the power to a device inside an experimental apparatus or a home cage. This technique suffers from a lower operational distance than far-field RF communication. The wireless head-mountable device in ref [36], for instance, receives the peak magnetic field when it is at the height of 0.5 to $2 \mathrm{~cm}$ above the induction platform, with a reduction of $30 \%$ at $3 \mathrm{~cm} \mathrm{[76].} \mathrm{The} \mathrm{operational} \mathrm{distance} \mathrm{is} \mathrm{a}$ function of the transmitted power; the power level must be substantially smaller than the maximum permissible exposure limits $\left(3.03 \mathrm{~mW} / \mathrm{cm}^{2}\right)$ for humans in controlled environment [15], and $1.6 \mathrm{~W} / \mathrm{Kg}$ for specific absorption rate (SAR) averaged over $1 \mathrm{~g}$ of tissue $[69,77,78]$. On the other side, despite the need to be periodically replaced or recharged, batteries are a reliable approach to deliver a relatively high-power for a wide volume light delivery system, with a small-enough headstage as in the case of our work. In general, batteries are preferred for behavior experiments over animals that may need a further communication range such as songbirds [79], flying bats [80], rats [81], mice [37], cats [82] and monkeys [83-85]. Here, batteries represent $60 \%$ of the total weight of our system. This leaves a room for improvement by working on enhancing the coupling efficiency between the TF and LD, which will directly 
help in lowering the power consumption and consequently the total size and weight. The size of the headstage $(14.0 \times 13.5$ $\mathrm{mm}^{2}$ ) is comparable with the size of other systems proposed in the literature (see the detailed comparison in Table III) and, as shown by the dimensions in Fig8. It fits in the size of the skull of adult (60 postnatal days) male C57BL/6J mice (width: 11.5 $\mathrm{mm}$, ventral length: $17.0 \mathrm{~mm}$, dorsal length: $22.0 \mathrm{~mm}$ for a 60 postnatal days male C57BL/6J [86]). Replacing batteries with a WPT system may help in reducing the total weight; however, it may shorten the wireless range as well as the pulse width of the generated pulses.

\section{Wireless communication}

The stimulation parameters (frequency, duty cycle, and pulse duration) are transmitted to the headstage wirelessly by infrared at $\lambda \sim 950 \mathrm{~nm}$; the output power of the LD is regulated manually by the trimmer. The tiny size and the low mass of the IR receiver help in building a miniaturized headstage since the receiver is a single component. Moreover, the IR communication has the advantage of offering a reliable communication without interference with nearby radio frequency (RF) signals. The battery-powered IR wireless headstage is a versatile, flexible setup that can be adapted to different environments from a home cage to a freestyle maze; since the number of IR LEDs can be increased to cover any blind spot in the arena. IR is an inexpensive and easy technique for wireless communication that is widely used for short-range $(1-5 \mathrm{~m})$ communication $[35,37,39,87,88]$. IR light is very similar to visible light, except that it has a slightly longer wavelength, typically in the range of $940-950 \mathrm{~nm}$. This means IR is invisible to partially blind rats and mice with dichromatic vision [89] that creates a convenient wireless communication technique for free behavior readout experiments. IR communication is limited to line of sight whereas RF communication can achieve a higher range of communication and data rate without line of sight (see Table V). For wireless implantable devices RF communication is preferable for bi-directional communication. It requires taking into consideration RF signal orientation and polarization; therefore a careful antenna design is required [87]. There is an arising new networking technology called light fidelity Li-Fi [90-92], which may limit the domination of RF communication, since it claims that it is 100 times faster than the traditional WiFi and can offer a bi-directional communication. In future work, the principle of communication between the transmitter and the head-mountable device can be integrated to a Li-Fi setup for mice in vivo arena for high data rate transmission.

\section{CONCLUSION}

The system presented in this work exploits the unconventional coupling of a semiconductor LD to TF on a wireless-driven platform to obtain wide-volume illumination in deep-brain regions, an approach so far limited to optogenetic tethering stimulation techniques. The system has a low total cost since it employs a cost-effective LD and commercially available components. Moreover, setting up the coupling between a semiconductor $\mathrm{LD}$ and $\mathrm{TF}$ on a self-consistent wireless platform opens the door for more complex light delivery modulation along the taper segment.

\section{ACKNOWLEDGEMENT}

The Authors would like to thank E. Maglie, A. Della Patria, and B. Spagnolo for fruitful discussions. The authors are also grateful to the anonymous reviewers for their insightful comments and suggestions. M.P., L.S. and M.D.V. acknowledge funding from the US National Institutes of Health (U01NS094190); F. P. acknowledges funding from the European Research Council under the European Union's Horizon 2020 research and innovation program (\#677683). M.D.V and F. P. have contributed equally to this work.

\section{APPENDIX}

To estimate the light power density (intensity, $p$ ) around the TF for a given total output power, at a certain coupling position, we use the system depicted in Fig S1. Under the assumption of a perfectly axially symmetrical light power distribution, $p(r, \emptyset, z)$, around the taper, and by using the intensity profile extracted from the light emission of TF in a PBS:fluorescein solution (e.g. Fig5 (a)), $p$ can be estimated. The total output power radiated from the taper surface $P$ can be expressed as:

$$
P=\int p(r, \emptyset, z) d \Sigma
$$

Where $\Sigma$ represents the taper surface. Considering that $p$ is assumed to be constant with respect to $\emptyset, r=z \tan (\psi / 2)$ on the taper surface, and

$$
d \Sigma=2 \pi z \tan \frac{\psi}{2}\left[\cos \frac{\psi}{2}\right]^{-1} d z
$$

It follows

$$
P=2 \pi \tan \frac{\psi}{2}\left[\cos \frac{\psi}{2}\right]^{-1} \int_{0}^{L} z p(z) d z
$$

Since the integral in (3) can be numerically estimated starting from the normalized experimental profile, $P_{\text {norm }}(z)$, with exception for a multiplicative constant, the estimation of the power density distribution along one arbitrary ruling of the conical surface can be obtained as

$$
p(z)=\frac{P}{2 \pi}\left[\int_{0}^{L^{\prime}} z P_{\text {norm }}(z) d z\right]^{-1} \cos \frac{\psi}{2}\left[\tan \frac{\psi}{2}\right]^{-1} P_{\text {norm }}(z) .
$$

$L^{\prime}$, represents the length of the line along the TF, where the intensity profile is collected (e.g. the cyan line in the bright field image in Fig5 (a). Fig5 (b) shows the result of such estimation for $0.39 \mathrm{NA} \mathrm{TF}\left(\Psi \sim 4^{\circ}, \mathrm{L} \sim 2.7 \mp 0.1 \mathrm{~mm}\right)$, at coupling position \#4, for a given total output power $P=1.7 \mathrm{~mW}$. Fig.S2 shows another example of power distribution around the tapered segment of a TF with a lower angle ( $\left.\Psi \sim 3^{\circ}, \mathrm{L} \sim 3.2 \mp 0.1 \mathrm{~mm}\right)$. TFs with low taper angle distributes the power uniformly over larger surface with a lower power density near the tip.

\section{REFERENCES}

1. Deisseroth, K., Optogenetics. Nat Meth, 2011. 8(1): p. 26-29. 
2. Pisanello, M., et al. Photonic technologies for optogenetics. in Transparent Optical Networks (ICTON), 2014 16th International Conference on. 2014.

3. Adamantidis, A.R., et al., Neural substrates of awakening probed with optogenetic control of hypocretin neurons. Nature, 2007. 450(7168): p. 420-4.

4. $\quad$ Lobo, M.K., et al., Cell Type Specific Loss of BDNF Signaling Mimics Optogenetic Control of Cocaine Reward. Science (New York, N.Y.), 2010. 330(6002): p. 385-390.

5. Packer, A.M., B. Roska, and M. Hausser, Targeting neurons and photons for optogenetics. Nat Neurosci, 2013. 16(7): p. 805-815.

6. Boyden, E.S., et al., Millisecond-timescale, genetically targeted optical control of neural activity. Nat Neurosci, 2005. 8(9): p. 12631268.

7. Yizhar, O., et al., Optogenetics in neural systems. Neuron, 2011. 71(1): p. 9-34.

8. Sileo, L., et al. Optical fiber technologies for in-vivo light delivery and optogenetics. in Transparent Optical Networks (ICTON), 2015 17th International Conference on. 2015.

9. Segev, E., et al., Patterned photostimulation via visible-wavelength photonic probes for deep brain optogenetics. Neurophotonics, 2016. 4(1): p. 011002-011002.

10. Pisanello, F., L. Sileo, and M. De Vittorio, Micro- and Nanotechnologies for Optical Neural Interfaces. Frontiers in Neuroscience, 2016. 10(70).

11. McAlinden, N., et al., Thermal and optical characterization of micro-LED probes for in vivo optogenetic neural stimulation. Optics Letters, 2013. 38(6): p. 992-994.

12. McCall, J.G., et al., Fabrication and application of flexible, multimodal light-emitting devices for wireless optogenetics. Nat. Protocols, 2013. 8(12): p. 2413-2428.

13. McAlinden, N., et al., Optogenetic activation of neocortical neurons in vivo with a sapphire-based micro-scale LED probe. Front Neural Circuits, 2015. 9: p. 25.

14. Scharf, R., et al., Depth-specific optogenetic control in vivo with a scalable, high-density $\mu L E D$ neural probe. Scientific Reports, 2016. 6: p. 28381.

15. Kim, T.I., et al., Injectable, cellular-scale optoelectronics with applications for wireless optogenetics. Science, 2013. 340(6129): p. 211-6.

16. Ayub, S., et al., An Intracerebral Probe with Integrated $10 \times 1 \mu L E D$ Array for Optogenetic Experiments at $460 \mathrm{~nm}$. Procedia Engineering, 2015. 120: p. 472-475.

17. Ayub, S., et al. High-density probe with integrated thin-film micro light emitting diodes ( $\mu L E D s)$ for optogenetic applications. in 2016 IEEE 29th International Conference on Micro Electro Mechanical Systems (MEMS). 2016.

18. Wu, F., et al., Monolithically Integrated $\mu L E D$ s on Silicon Neural Probes for High-Resolution Optogenetic Studies in Behaving Animals. Neuron, 2015. 88(6): p. 1136-1148.

19. Zorzos, A.N., E.S. Boyden, and C.G. Fonstad, Multiwaveguide implantable probe for light delivery to sets of distributed brain targets. Optics Letters, 2010. 35(24): p. 4133-4135.

20. Zorzos, A.N., et al., 3-Dimensional Multiwaveguide Probe Array for Light Delivery to Distributed Brain Circuits. Optics letters, 2012. 37(23): p. 4841-4843.

21. Pisanello, F., et al., Multipoint-emitting optical fibers for spatially addressable in vivo optogenetics. Neuron, 2014. 82(6): p. 1245-54. Pisanello, M., et al., Modal demultiplexing properties of tapered and nanostructured optical fibers for in vivo optogenetic control of neural activity. Biomedical Optics Express, 2015. 6(10): p. 4014.

23. Acker, L., et al., FEF inactivation with improved optogenetic methods. Proceedings of the National Academy of Sciences, 2016. 113(46): p. E7297-E7306.

24. Park, S., et al., One-step optogenetics with multifunctional flexible polymer fibers. Nat Neurosci, 2017. advance online publication.

25. Pisanello, F., et al., Dynamic illumination of spatially restricted or large brain volumes via a single tapered optical fiber. Nat Neurosci, 2017. advance online publication.

26. Lu, C., et al., Flexible and stretchable nanowire-coated fibers for optoelectronic probing of spinal cord circuits. Science Advances, 2017. 3(3).

27. Ki Yong, K., et al. Integrated slanted microneedle-LED array for optogenetics. in Engineering in Medicine and Biology Society
(EMBC), 2013 35th Annual International Conference of the IEEE. 2013.

28. Kwon, K.Y., et al. Head-mounted LED for optogenetic experiments of freely-behaving animal. 2016.

29. Park, S.I., et al., Soft, stretchable, fully implantable miniaturized optoelectronic systems for wireless optogenetics. Nat Biotech, 2015. 33(12): p. 1280-1286.

30. Montgomery, K.L., et al., Wirelessly powered, fully internal optogenetics for brain, spinal and peripheral circuits in mice. Nat Meth, 2015. 12(10): p. 969-974.

31. Yeh, A.J., et al., Wirelessly powering miniature implants for optogenetic stimulation. Applied Physics Letters, 2013. 103(16): p. 163701.

32. Shin, G., et al., Flexible Near-Field Wireless Optoelectronics as Subdermal Implants for Broad Applications in Optogenetics. Neuron, 2017. 93(3): p. 509-521.e3.

33. Noh, K.N., et al., Miniaturized, Battery-Free Optofluidic Systems with Potential for Wireless Pharmacology and Optogenetics. Small, 2018. 14(4): p. 1702479-n/a.

34. Park, S.I., et al., Stretchable multichannel antennas in soft wireless optoelectronic implants for optogenetics. Proceedings of the National Academy of Sciences, 2016. 113(50): p. E8169-E8177.

35. Iwai, Y., et al., A simple head-mountable LED device for chronic stimulation of optogenetic molecules in freely moving mice. Neurosci Res, 2011. 70(1): p. 124-7.

36. Wentz, C.T., et al., A wirelessly powered and controlled device for optical neural control of freely-behaving animals. Journal of Neural Engineering, 2011. 8(4): p. 046021.

37. Hashimoto, M., et al., Programmable wireless light-emitting diode stimulator for chronic stimulation of optogenetic molecules in freely moving mice. Neurophotonics, 2014. 1(1): p. 011002.

38. Yuan, M., et al. A wirelessly controlled optical stimulator for optogenetics application. in 2015 IET International Conference on Biomedical Image and Signal Processing (ICBISP 2015). 2015.

39. Jeong, J.-W., et al., Wireless Optofluidic Systems for Programmable In Vivo Pharmacology and Optogenetics. Cell, 2015. 162(3): p. 662674.

40. Rossi, M.A., et al., A wirelessly controlled implantable LED system for deep brain optogenetic stimulation. Frontiers in Integrative Neuroscience, 2015. 9: p. 8.

41. Sung Il, P., et al., Ultraminiaturized photovoltaic and radio frequency powered optoelectronic systems for wireless optogenetics. Journal of Neural Engineering, 2015. 12(5): p. 056002.

42. McCall, J.G., et al., Preparation and implementation of optofluidic neural probes for in vivo wireless pharmacology and optogenetics. Nature Protocols, 2017. 12: p. 219.

43. $\quad \mathrm{Lu}, \mathrm{L}$., et al., Wireless optoelectronic photometers for monitoring neuronal dynamics in the deep brain. Proceedings of the National Academy of Sciences, 2018. 115(7): p. E1374-E1383.

44. Ameli, R., et al. A wireless and batteryless neural headstage with optical stimulation and electrophysiological recording. in 2013 35th Annual International Conference of the IEEE Engineering in Medicine and Biology Society (EMBC). 2013.

45. Gagnon-Turcotte, G., et al., A Wireless Optogenetic Headstage with Multichannel Electrophysiological Recording Capability. Sensors, 2015. 15(9): p. 22776.

46. Dagnew, R., et al. CerebraLux: a low-cost, open-source, wireless probe for optogenetic stimulation. 2017. SPIE.

47. Gagnon-Turcotte, G., et al., A Wireless Headstage for Combined Optogenetics and Multichannel Electrophysiological Recording. IEEE Transactions on Biomedical Circuits and Systems, 2017. 11(1): p. 1-14.

48. Lee, S.T., et al., A Miniature, Fiber-Coupled, Wireless, Deep-Brain Optogenetic Stimulator. IEEE Transactions on Neural Systems and Rehabilitation Engineering, 2015. 23(4): p. 655-664.

49. Maghsoudloo, E., et al. A Smart Neuroscience Platform with Wireless Power Transmission for Simultaneous Optogenetics and Electrophysiological Recording. in 2018 IEEE International Symposium on Circuits and Systems (ISCAS). 2018.

50. Kwon, K.Y., et al. A wireless slanted optrode array with integrated micro leds for optogenetics. in 2014 IEEE 27th International Conference on Micro Electro Mechanical Systems (MEMS). 2014.

51. Lee, H.M., et al. A wireless implantable switched-capacitor based optogenetic stimulating system. in 2014 36th Annual International 
Conference of the IEEE Engineering in Medicine and Biology Society. 2014.

52. Kwon, K.Y., et al., Design, fabrication, and packaging of an integrated, wirelessly-powered optrode array for optogenetics application. Front Syst Neurosci, 2015. 9: p. 69.

53. Schwaerzle, M., et al. Miniaturized tool for optogenetics based on an LED and an optical fiber interfaced by a silicon housing. in 2014 36th Annual International Conference of the IEEE Engineering in Medicine and Biology Society. 2014.

54. Bi, X., et al., A Flexible, Micro-Lens-Coupled LED Stimulator for Optical Neuromodulation. IEEE Transactions on Biomedical Circuits and Systems, 2016. PP(99): p. 1-7.

55. Stark, E., T. Koos, and G. Buzsaki, Diode probes for spatiotemporal optical control of multiple neurons in freely moving animals. J Neurophysiol, 2012. 108(1): p. 349-63.

56. Cao, H., et al., An Integrated $\mu L E D$ Optrode for Optogenetic Stimulation and Electrical Recording. IEEE Transactions on Biomedical Engineering, 2013. 60(1): p. 225-229.

57. $\mathrm{Li}, \mathrm{Y}$. , et al., Thermal analysis of injectable, cellular-scale optoelectronics with pulsed power. Proceedings of the Royal Society A: Mathematical, Physical and Engineering Science, 2013. 469(2157).

58. Gagnon-Turcotte, G., et al. A wireless photostimulator for optogenetics with live animals. in 2017 15th IEEE International New Circuits and Systems Conference (NEWCAS). 2017.

59. Bi, X., B. Fan, and W. Li. Micro-lens-coupled LED neural stimulator for optogenetics. in 2015 IEEE Biomedical Circuits and Systems Conference (BioCAS). 2015.

60. Blue Laser Diode in TO38 ICut PAckage (PL 450B, OSRAM) (2017, August 04). Retrieved from https://www.osramos.com/Graphics/XPic1/00246126_0.pdf/PL\%20450B.pdf. 2015.

61. Leifer, A.M., et al., Optogenetic manipulation of neural activity in freely moving Caenorhabditis elegans. Nat Meth, 2011. 8(2): p. 147-152.

62.

Bruegmann, T., et al., Optogenetic control of contractile function in skeletal muscle. Nat Commun, 2015. 6: p. 7153.

63. Taslimi, A., et al., An optimized optogenetic clustering tool for probing protein interaction and function. Nat Commun, 2014. 5: p. 4925.

64. Alexander, M.A., et al., An optical neural interface: in vivo control of rodent motor cortex with integrated fiberoptic and optogenetic technology. Journal of Neural Engineering, 2007. 4(3): p. S143.

65. Fan, F., et al., A monolithic white laser. Nat Nanotechnol, 2015. 10(9): p. 796-803.

66. Rossi, M.A., N. Calakos, and H.H. Yin, Spotlight on movement disorders: What optogenetics has to offer. Mov Disord, 2015. 30(5): p. 624-31.

67. Childs, C., Human brain temperature: regulation, measurement and relationship with cerebral trauma: Part 1. British Journal of Neurosurgery, 2008. 22(4): p. 486-496.

68. Andersen, P. and E.I. Moser, Brain temperature and hippocampal function. Hippocampus, 1995. 5(6): p. 491-498.

69. Aldaoud, A., et al., Wireless multichannel optogenetic stimulators enabled by narrow bandwidth resonant tank circuits. Sensors and Actuators A: Physical, 2018. 271: p. 201-211.

70. Gagnon, L.L., et al. A wireless system for combined heart optogenetics and electrocardiography recording. in 2017 IEEE International Symposium on Circuits and Systems (ISCAS). 2017.

71. Gagnon-Turcotte, G., et al. Wireless brain computer interfaces enabling synchronized optogenetics and electrophysiology. in 2017 IEEE International Symposium on Circuits and Systems (ISCAS). 2017.

72. Ahire, D.B. and V.J. Gond. Wireless power transfer system for biomedical application: A review. in 2017 International Conference on Trends in Electronics and Informatics (ICEI). 2017.

73. Chang, C.-W. and J.-C. Chiou, A Wireless and Batteryless Microsystem with Implantable Grid Electrode/3-Dimensional Probe Array for ECoG and Extracellular Neural Recording in Rats. Sensors, 2013. 13(4): p. 4624.

74. Merli, F., et al., Design, Realization and Measurements of a Miniature Antenna for Implantable Wireless Communication Systems. IEEE Transactions on Antennas and Propagation, 2011. 59(10): p. 3544-3555.
75.

.

Gutruf, P. and J.A. Rogers, Implantable, wireless device platforms for neuroscience research. Current Opinion in Neurobiology, 2018. 50: p. $42-49$.

Warden, M.R., J.A. Cardin, and K. Deisseroth, Optical Neural Interfaces. Annual review of biomedical engineering, 2014. 16: p. 103-129.

Hsing-Yi, C. and W. Hou-Hwa, Current and SAR induced in a human head model by the electromagnetic fields irradiated from a cellular phone. IEEE Transactions on Microwave Theory and Techniques, 1994. 42(12): p. 2249-2254.

IEEE Standard for Safety Levels With Respect to Human Exposure to Radio Frequency Electromagnetic Fields, $3 \mathrm{kHz}$ to $300 \mathrm{GHz}$. IEEE Std C95.1-1991, 1992: p. 1.

Arfin, S.K., et al., Wireless Neural Stimulation in Freely Behaving Small Animals. Journal of Neurophysiology, 2009. 102(1): p. 598605.

Lancaster, W.C., O.W. Henson, and A.W. Keating, Respiratory muscle activity in relation to vocalization in flying bats. The Journal of Experimental Biology, 1995. 198(1): p. 175-191.

Su, K., et al., A wearable wireless system for olfactory neural recording in freely moving rats based on Wi-Fi technology. Sensors and Actuators B: Chemical, 2015. 213(Supplement C): p. 457-464. Sherk, H. and E.J. Wilkinson, A novel system for recording from single neurons in unrestrained animals. Journal of Neuroscience Methods, 2008. 173(2): p. 201-207.

Miranda, H., et al. A high-rate long-range wireless transmission system for multichannel neural recording applications. in 2009 IEEE International Symposium on Circuits and Systems. 2009.

Mavoori, J., et al., An autonomous implantable computer for neural recording and stimulation in unrestrained primates. Journal of Neuroscience Methods, 2005. 148(1): p. 71-77.

Lei, Y., et al., Telemetric recordings of single neuron activity and visual scenes in monkeys walking in an open field. Journal of Neuroscience Methods, 2004. 135(1): p. 35-41.

Maga, A.M., Postnatal Development of the Craniofacial Skeleton in Male C57BL/6J Mice. Journal of the American Association for Laboratory Animal Science : JAALAS, 2016. 55(2): p. 131-136. McCall, J.G. and J.-W. Jeong, Minimally invasive probes for programmed microfluidic delivery of molecules in vivo. Current Opinion in Pharmacology, 2017. 36: p. 78-85.

Sim, J.Y., et al., Microfluidic neural probes: in vivo tools for advancing neuroscience. Lab on a Chip, 2017. 17(8): p. 1406-1435. Jacobs, G.H., J.A. Fenwick, and G.A. Williams, Cone-based vision of rats for ultraviolet and visible lights. Journal of Experimental Biology, 2001. 204(14): p. 2439-2446.

Vijayalakshmi, A. and N. Sudha. New strategy in wireless communication: Li-Fi for delivery of broadband and media content in aircraft without intrusion. in 2017 International Conference on Wireless Communications, Signal Processing and Networking (WiSPNET). 2017.

Sahrawat, P.K. Li-Fi: Future of Wireless Communication. in National Conference on Innovative Trends in Computer Science Engineering (ITCSE-2015). 2015.

Haas, H. High-speed wireless networking using visible light. SPIE, 2013.

Hassan, S.M., et al., Application of Wireless Technology for Control: A WirelessHART Perspective. Procedia Computer Science, 2017. 105: p. 240-247.

Abinayaa, V. and A. Jayan, Case Study on Comparison of Wireless TEchnologies in Industrial Applications. International Journal of Scientific and Research Publications, 2014. 4(2).

Zatout, Y. Using wireless technologies for healthcare monitoring at home: A survey. in 2012 IEEE 14th International Conference on eHealth Networking, Applications and Services (Healthcom). 2012. Comission, F.C., Human Exposure to Radiofrequency

Electromagnetic Fields 2013.

333(6044): p. 838-843.

Jang, K.-I., et al., Rugged and breathable forms of stretchable electronics with adherent composite substrates for transcutaneous monitoring. Nature Communications, 2014. 5: p. 4779.

Xu, S., et al., Soft Microfluidic Assemblies of Sensors, Circuits, and Radios for the Skin. Science, 2014. 344(6179): p. 70-74. 
100. Cecil, S., et al. Numerical Assessment of Specific Absorption Rate in the Human Body Caused by NFC Devices. in 2010 Second International Workshop on Near Field Communication. 2010.

101. Fan, D., et al., A Wireless Multi-Channel Recording System for Freely Behaving Mice and Rats. PLoS ONE, 2011. 6(7): p. e22033.

102. Szuts, T.A., et al., A wireless multi-channel neural amplifier for freely moving animals. Nat Neurosci, 2011. 14(2): p. 263-9.

103. Hampson, R.E., V. Collins, and S.A. Deadwyler, A wireless recording system that utilizes Bluetooth technology to transmit neural activity in freely moving animals. Journal of Neuroscience Methods, 2009. 182(2): p. 195-204.

104. Obeid, I., M.A.L. Nicolelis, and P.D. Wolf, A multichannel telemetry system for single unit neural recordings. Journal of Neuroscience Methods, 2004. 133(1): p. 33-38.

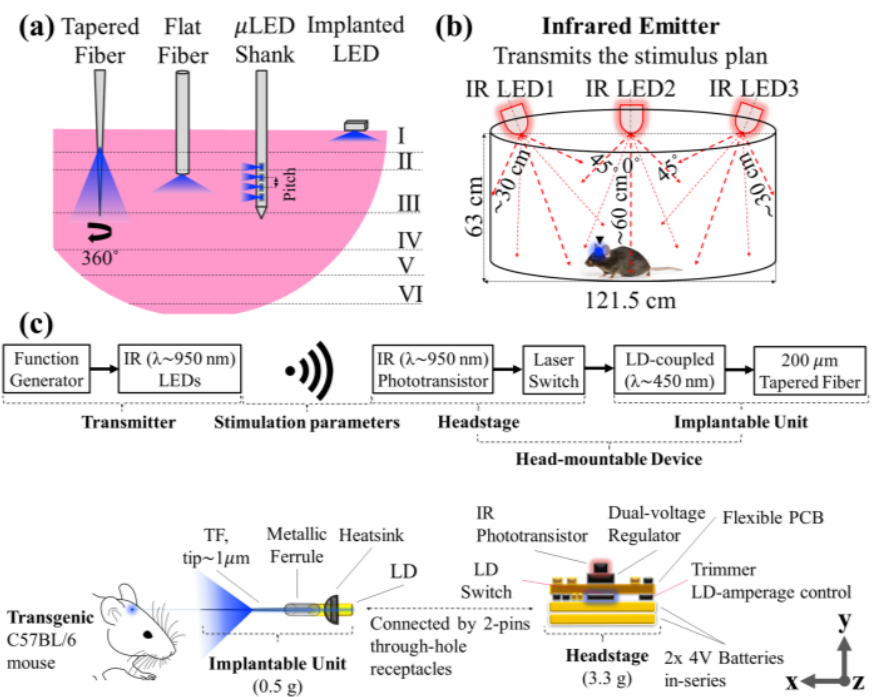

(d) F: $200 \mathrm{~Hz}, \mathrm{D}: \mathbf{1 0} \%$, ON: $500 \mu \mathrm{s}, 40$ Pulses

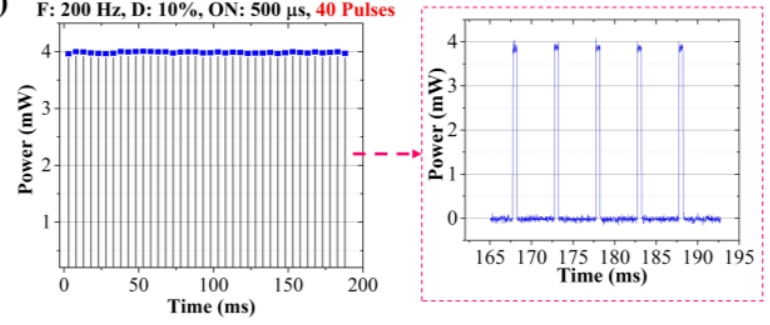

Fig. 1. System overview

(a) Schematic comparison between the different capabilities for each light delivery system. The implantable LEDs are ideal for stimulating the superficial cortical layers whereas the other systems are for deeper regions. However, TF are ideal for deeper regions since they are minimal invasive and offers a large illuminated volume. (b) Sketch of the proposed wireless optogenetic system. The IR emitter sends the stimulus parameters to a head-mountable device fixed on the head of a transgenic mouse. (c) System block diagram and data flow from the function generator until it reaches the implantable TF. (d) $4 \mathrm{~mW}$ output power pulses emitted by the head-mountable device at TTL trigger signal (F: $200 \mathrm{~Hz}, \mathrm{D}: 10 \%$, Pulse-width: $500 \mu \mathrm{s})$. (a)

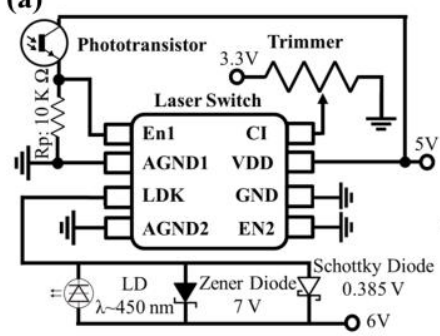

(c)

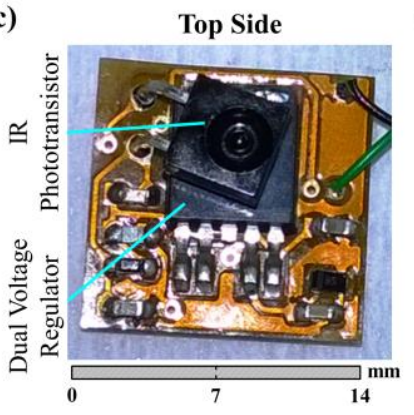

(b)

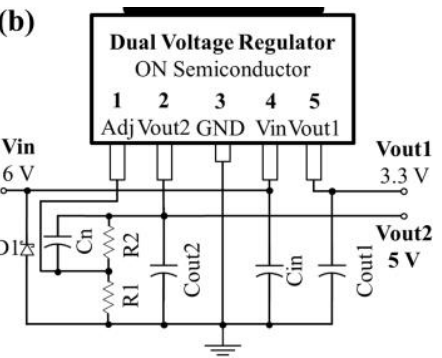

(d) Bottom Side

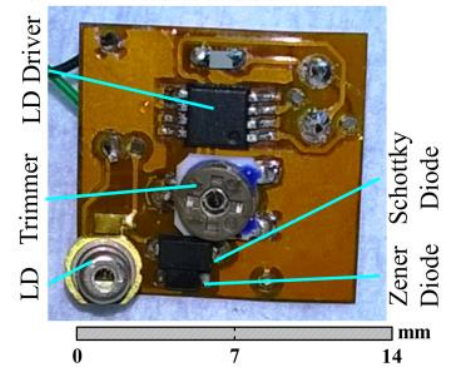

Fig. 2. Headstage circuit diagram

(a) Circuit diagram of the laser driving circuit on the headstage (top-copper), which comprises the laser diode switch, the output optical power tuning trimmer, the laser diode protection circuit, and the receptacles for connecting the headstage to the implantable unit. (b) Circuit diagram of the power module on the headstage (bottom-copper), which compromises the dual voltage regulator, the IR phototransistor receiver, and the battery terminals. (c-d) Two photographs of top and bottom sides of the headstage after hand-soldering all the components.

(a)

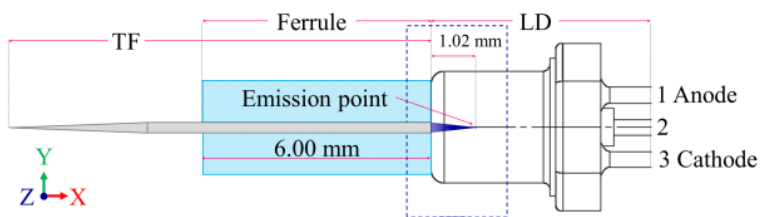

\begin{tabular}{cc:cc:c} 
At $\boldsymbol{\theta}_{\perp}: 25^{\circ}$ & $\theta_{\text {Full }}=2 \times \theta_{\perp}$ & At $\boldsymbol{\theta}_{\|}: 11^{\circ}$ & $\theta_{\text {Full }}=2 \times \theta_{\|}$ & Fiber Core $0.1 \mathrm{~mm}$ \\
\hline
\end{tabular}

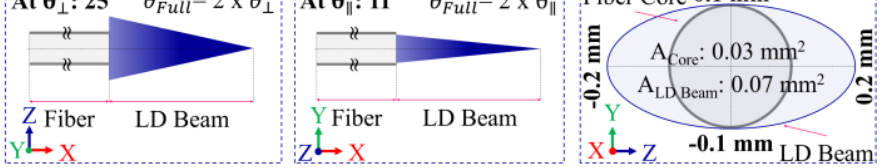

(b)

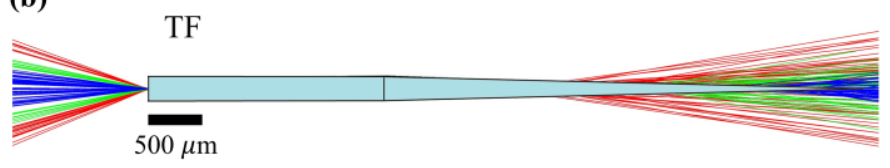

Fig. 3. Headstage circuit diagram

(a) Schematic side view of the coupling between the LD and TF connectorized to a corresponding metallic ferrule. Below are the launching conditions between the $\mathrm{LD}$ beam (maximum divergence angles at FWHM, $\theta_{\perp} \times \theta_{/ /}: 25^{\circ} \times 11^{\circ}$ ) and TF core $(\varnothing 200 \mu \mathrm{m})$. (b) Ray tracing schematic of the implantable 0.39 NA tapered fiber. Red, green, and blue rays at high, low, and almost at the center injected angles to the fiber facet respectively. Rays with higher injected angles are out-coupled further from the tip: the higher the injected angle, the further out-coupled ray from the tip. 


\section{(a)}

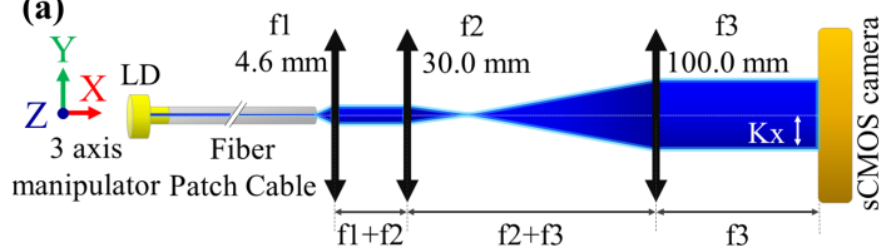

(b)

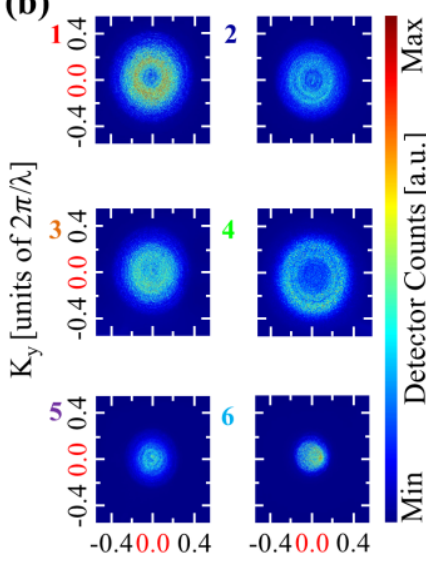

$\mathrm{K}_{\mathrm{x}}$ [units of $\left.2 \pi / \lambda\right]$ (c)

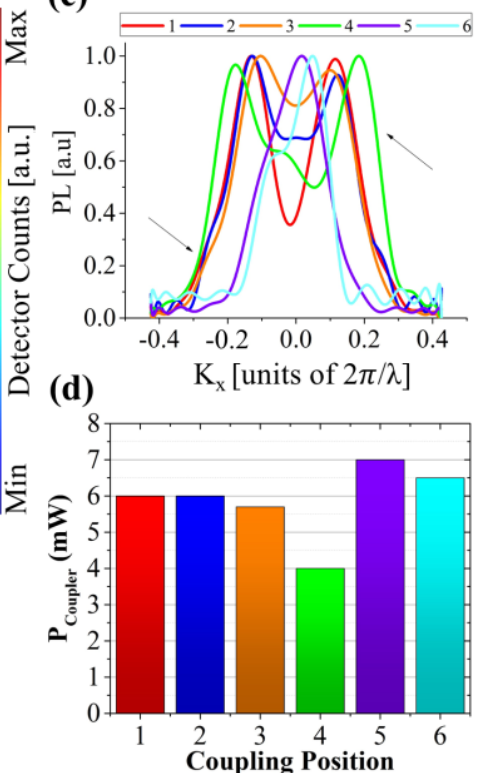

Fig. 4. The optical properties of the coupler

(a) Schematic of the optical setup for collecting far fields images of the fiber end facet by sCMOS camera. The laser diode (LD) is set on 3-axis micromanipulator and coupled to a fixed 0.39 NA optical fiber patch cable $(200 / 225 \mu \mathrm{m})$. The movement of the LD over the 3-axis micromanipulator in respect to the fixed optical fiber changes coupling position and therefore changes the injected guided modes into the fiber. (b) Far field images of the fiber output end facet at six different coupling positions with respect to the wave vector axis $K_{Y} \& K_{X}$. (c) Superposition of the six coupling positions with respect to the $K_{x}$ axis. The graph of each coupling position is identified by a different color to facilitate the comparison between the different coupling positions according to the output power and the width with respect to the wave-vector values. The coupling position \# 4 is the widest along the $K_{x}$ axis. (d) Total collected output optical power $\left(\mathrm{P}_{\text {Coupling }}\right.$ ) for each coupling position with the corresponding number and color. The highest measured power level was at coupling position no. 5 .

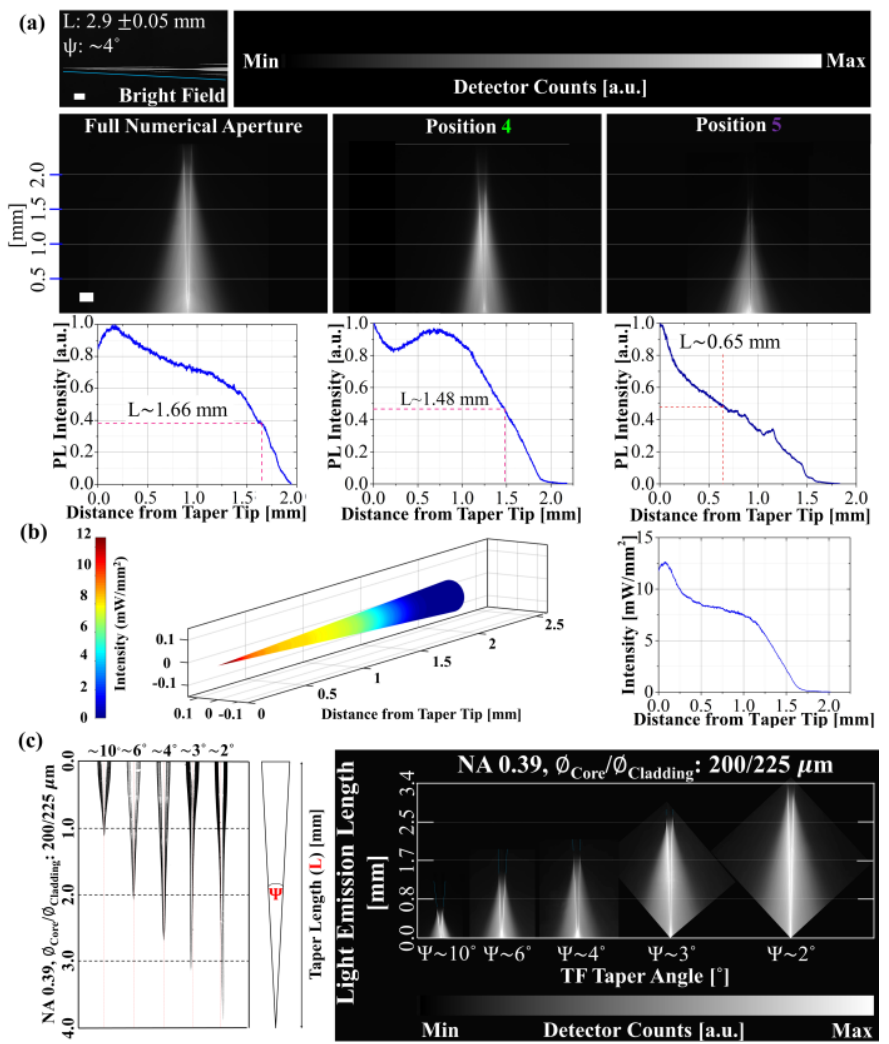

Fig. 5. The achieved light emission out of the coupler

(a) Light emission out of TF with taper angle $\Psi \sim 4^{\circ}$ at three different coupling positions. Full Numerical Aperture position (far left), obtained by using table top optical mounts, resulting emission length is $\mathrm{L} \sim 1.66 \mathrm{~mm}$. Coupling position no. 4 achieves $\mathrm{L} \sim 1.48 \mathrm{~mm}$ light emission length. Coupling position no. 5 achieves L $\sim 0.65 \mathrm{~mm}$ light emission length. All the profiles were collected along the cyan line in the bright field image. Scale bar is $200 \mu \mathrm{m}$. (b) The power density along and around the $\mathrm{TF}\left(\Psi \sim 4^{\circ}, \mathrm{L} \sim 2.7 \pm 0.1 \mathrm{~mm}\right)$ at coupling position no. 4. (c) Left, a group of TFs with different taper angles $\left(\Psi \sim 10\right.$ to $\left.2^{\circ}\right)$. Right, the same group of tapers coupled at position no. 4 then submerged in a droplet of PBS:fluorescein solution to the show the regulation of the emission length with respect to the taper length and angle. 
(a)

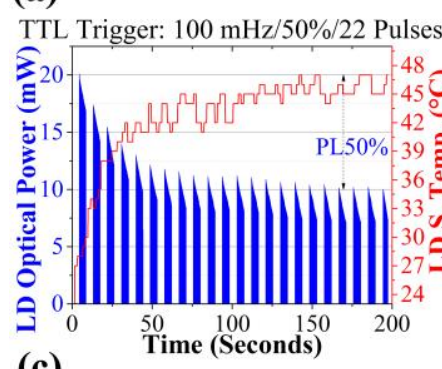

(c)

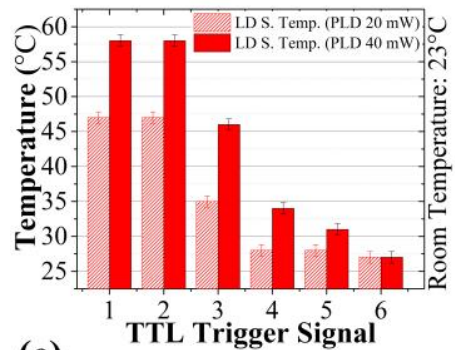

(e)

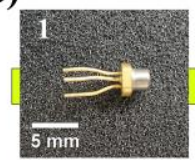

(f)

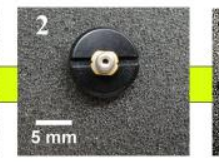

TTL Trigger: $100 \mathrm{mHz} / 50 \% / 22$ Pulses

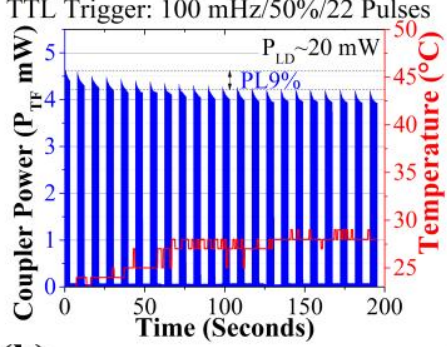

(h)

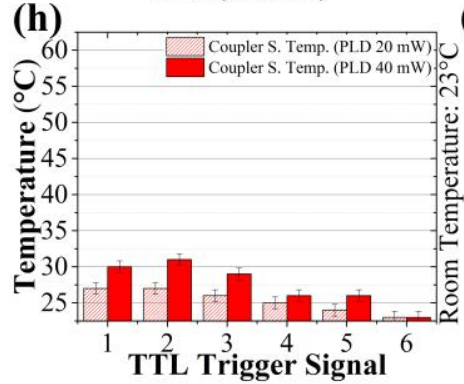

(i) 60

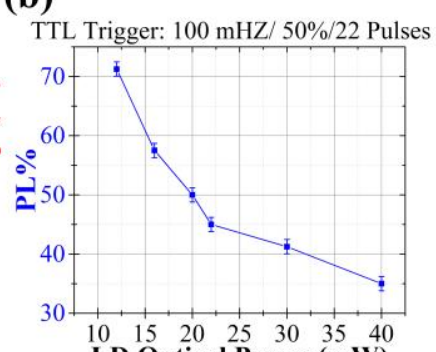

(d)
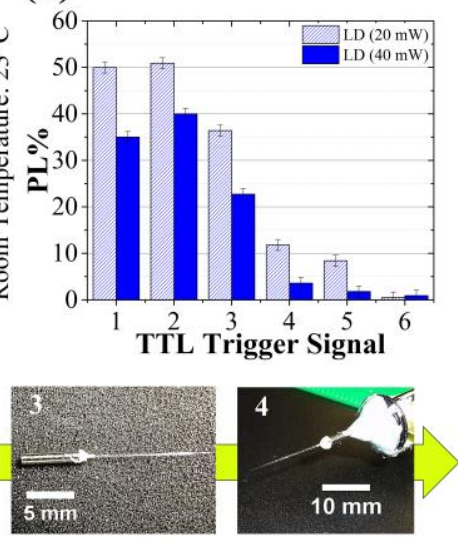

(g)
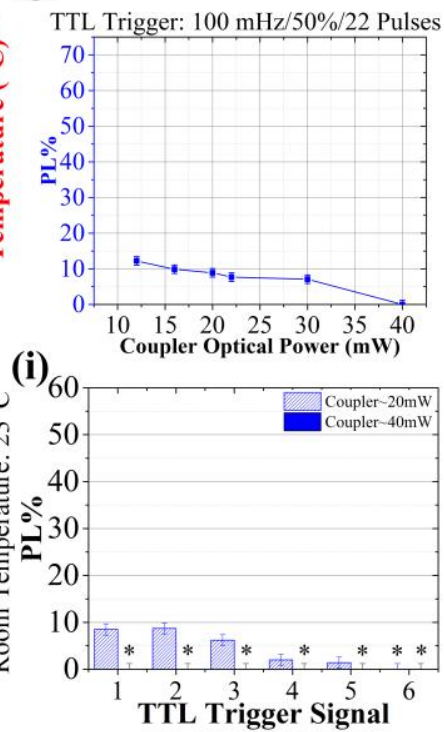

(a)

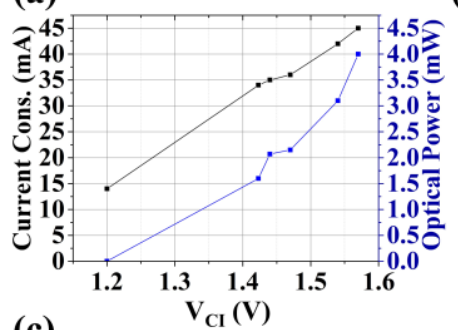

(c)

$625 \mathrm{mHz}, \mathrm{D}: 20 \%, \mathrm{ON}: 320 \mathrm{~ms}, 112$ Pulses
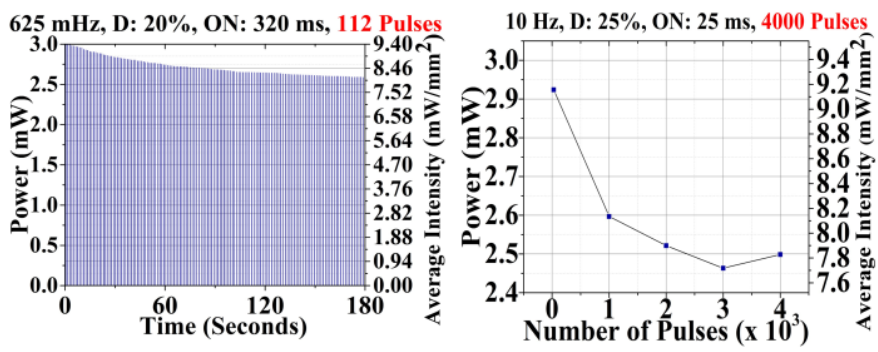

$200 \mathrm{~Hz}$, D: $10 \%$, ON: $500 \mu \mathrm{s}, 80000$ Pulses

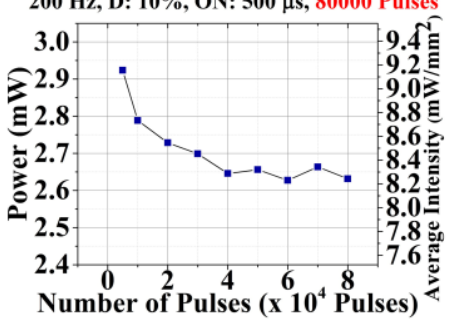

Fig. 7. Power consumption

(a) Relationship between the total current consumption of the headstage and the $\mathrm{P}_{\mathrm{TF}}$ (the emitted power at the TF tip) at different values of the regulating $\mathrm{V}_{\mathrm{CI}}$ of the laser switch. (b) The energy consumption $(\mathrm{J})$ at the end of 3 minutes of continuous operation for different optical power intensities at different TTL trigger signal with different duty cycles (D). (c) Left-top graph shows $\mathrm{P}_{\mathrm{TF}}$ and the average power intensity along 3 minutes of continuous operation at TTL trigger signal $625 \mathrm{mHz} / 20 \% / 320 \mathrm{~ms}$. Right-top graph shows the $\mathrm{P}_{\mathrm{TF}}$ and the average intensity at TTL $10 \mathrm{~Hz} / 25 \% / 25 \mathrm{~ms}$ along 4000 pulses, each blue dot represents the average of $\mathrm{P}_{\mathrm{TF}}$ and intensity after multiple 1000 pulses of $75 \mathrm{~ms}$. Left-down shows the same parameters at TTL $200 \mathrm{~Hz} / 10 \% / 500 \mu$ s along 80,000 pulses, each blue dot represents the average of $\mathrm{P}_{\mathrm{TF}}$ and intensity after multiple 10,000 . In all the three figures, the head-mountable device was powered by two $3.7 \mathrm{~V} / 50 \mathrm{mAh}$ lithium polymer rechargeable batteries (GM051215, PowerStream).

Fig. 6. The implantable unit thermal properties

(a) Typical example of output optical power $\left(\mathrm{P}_{\mathrm{LD}}\right)$ and temperature of a bare laser diode cane $\left(\mathrm{T}_{\text {Case }}\right)$ along 3 minutes of continuous operation at TTL trigger signal: $100 \mathrm{mHz} / 50 \% / 22-P u l s e s$ (5s on \& 5s off). (b) Power loss percentage $(\mathrm{PL} \%)$ at six different output optical power $\left(\mathrm{P}_{\mathrm{LD}}\right)$ levels at the end of 3 minutes of continuous operation at TTL trigger signal: $100 \mathrm{mHz} / 50 \% / 22-\mathrm{Pulses}(5 \mathrm{~s}$ on \& 5s off). (c-d) $\mathrm{T}_{\text {case }}$ and PL\% for 3 minutes of continuous operation of a bare $\mathrm{LD}$ at $\mathrm{P}_{\mathrm{LD}} \sim 40 \mathrm{~mW}$ and $\mathrm{P}_{\mathrm{LD}} \sim 20 \mathrm{~mW}$ at six different TTL Trigger Signal: (1) $100 \mathrm{mHz} / 50 \%$, (2) $333 \mathrm{mHz} / 50 \%$, (3) $40 \mathrm{~Hz} / 40 \%$, (4) $10 \mathrm{~Hz} / 25 \%$, (5) 20 $\mathrm{Hz} / 20 \%$, (6) $30 \mathrm{~Hz} / 15 \%$. (e) The preparation of the implantable unit from a bare LED at (1) to a complete unit at (4). (f) Output optical power of the coupler $\left(\mathrm{P}_{\mathrm{TF}}\right)$, along with the surface temperature of the coupler, at $\mathrm{P}_{\mathrm{LD}} \sim 20 \mathrm{~mW}$. (g) Power loss percentage (PL\%), after the realization of the coupling as represented in panel e4. (h-i) Graphs exhibit the temperature of the diode laser case $\left(\mathrm{T}_{\text {case }}\right)$ and PL\% for 3 minutes of continuous operation after enhancing the heat dissipation, for the same TTL trigger signals of panels (c-d). Panels (a-d) can go in a direct comparison with panels (f-i) to show the difference in the optical and thermal characteristics before and after building a coupler. 


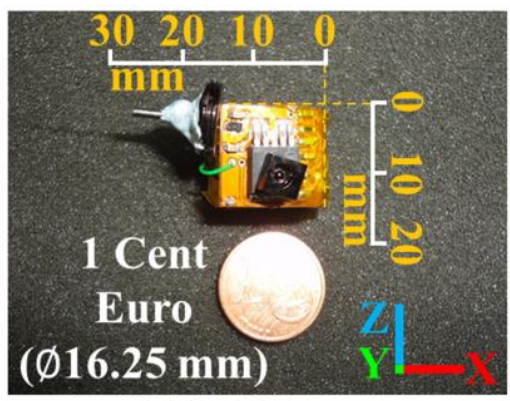

TOP View

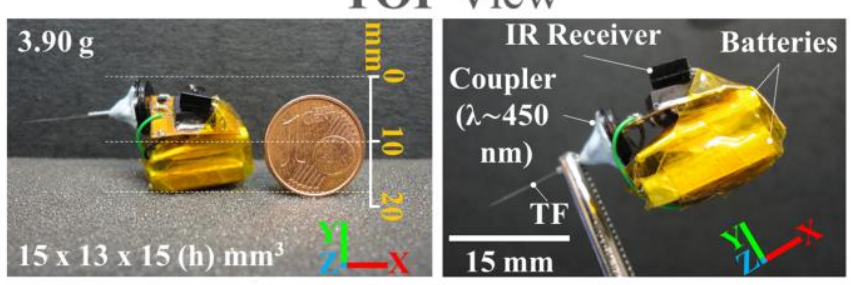

SIDE View

Fig. 8. The head-mountable device. Photos of different views of the complete head-mountable device.

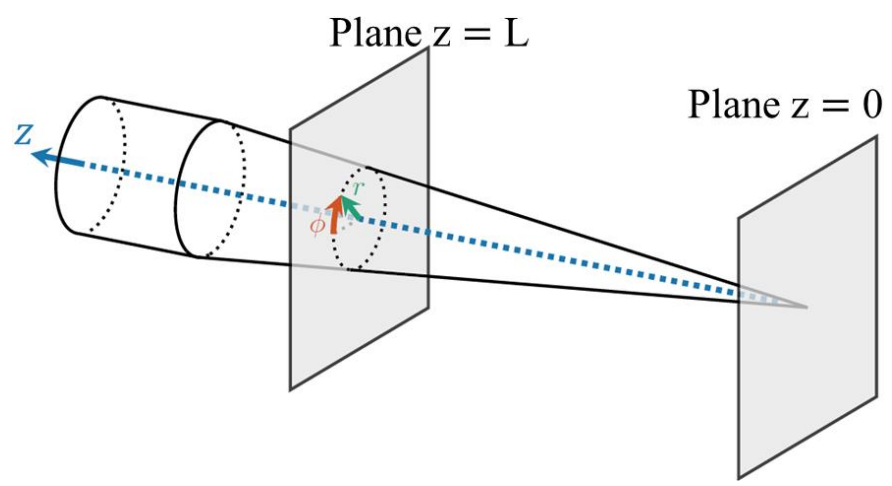

Fig. S1. Cylindrical coordinate system adopted for the estimation of light power density.

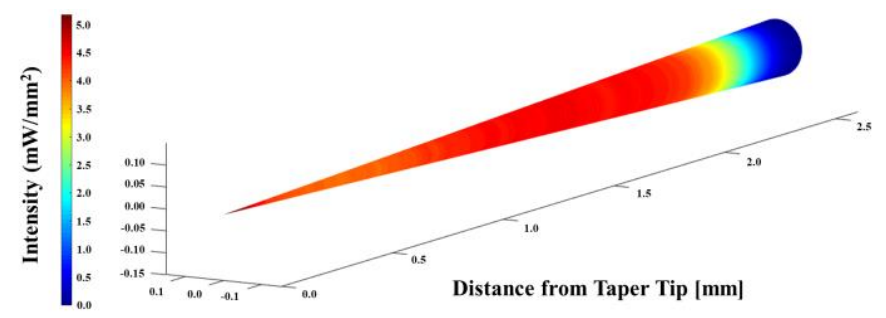

Fig. S2. The power density along and around the $\mathrm{TF}\left(\Psi \sim 3^{\circ}, \mathrm{L} \sim 3.2 \pm 0.1 \mathrm{~mm}\right)$ at coupling position no. 4 .

Table1

The weight of the head-mountable device

\begin{tabular}{|c|c|}
\hline \hline Component & Weight $(\mathrm{g})$ \\
\hline Headstage & 0.8 \\
\hline Coupler & 0.5 \\
\hline Battery $(\# 2)$ & 2.5 \\
\hline Total & 3.8 \\
\hline
\end{tabular}


TBME-01112-2018.R1

\begin{tabular}{|c|c|}
\hline \multicolumn{2}{|r|}{$\begin{array}{c}\text { Table II } \\
\text { System Characteristics }\end{array}$} \\
\hline Parameter & Value \\
\hline Input Voltage & $6 \mathrm{~V}$ \\
\hline Current Consumption (LD OFF) & $1 \mathrm{~mA}$ (LD_OFF) \\
\hline $\begin{array}{l}\text { Current Consumption } \\
\left(\mathrm{LD} \mathrm{ON}, 12.5 \mathrm{~mW} / \mathrm{mm}^{2}\right)\end{array}$ & $45 \mathrm{~mA}\left(12.5 \mathrm{~mW} / \mathrm{mm}^{2}\right)$ \\
\hline Light Source & Semiconductor Laser Diode (OSRAM, Q65111A0518, $\lambda \sim 450 \mathrm{~nm}$ ) \\
\hline Implantable TF & $\begin{array}{l}\text { 0.39 NA TF }(\varnothing 200 / 225 \mu \mathrm{m}) \\
\text { The light emission length along the tapered segment can be tailored from } \sim 400 \mu \mathrm{m} \text { to } \sim 3 \mathrm{~mm} \text { by acting } \\
\text { on the taper angle }\left(2^{\circ}<\Psi<10^{\circ}\right) \text {. }\end{array}$ \\
\hline Wireless TTL Trigger Signal & $\mathrm{IR}, \lambda \sim 950 \mathrm{~nm}$ \\
\hline Power source & $\begin{array}{l}\text { Two Batteries: } 3 \mathrm{~V}, 225 \mathrm{mAh} \text {, Lithium Manganese Dioxide Coin Button Battery (CR2032)(non- } \\
\text { rechargeable)(RS Pro, 866-0672), } 20 \text { x } 3.2 \mathrm{~mm} \text {, Weight (2 Batteries): } 6.2 \mathrm{~g} \\
\text { 2. Two Batteries: } 3 \mathrm{~V}, 140 \mathrm{mAh} \text {, Lithium Manganese Dioxide Coin Button Battery (CR2025) (non- } \\
\text { rechargeable) (RS Pro, 866-0663), } 20 \times 2.5 \mathrm{~mm} \text {, Weight (2 Batteries): } 4.40 \mathrm{~g} \\
\text { 3. Two Batteries: } 3.7 \mathrm{~V}, 50 \mathrm{mAh} \text {, Lithium ion Battery (rechargeable) (Powerstream, M041215), } 15 \mathrm{x} \\
12 \times 5 \mathrm{~mm} \text {, Weight (2 Batteries): } 2.5 \mathrm{~g}\end{array}$ \\
\hline $\begin{array}{l}\text { Head-mountable total weight according to } \\
\text { the used batteries }\end{array}$ & $\begin{array}{lr}\text { 1. } & 7.5 \mathrm{~g} \\
2 . & 5.7 \mathrm{~g} \\
\text { 3. } & 3.8 \mathrm{~g} \\
\end{array}$ \\
\hline $\begin{array}{l}\text { Battery life time at } 10 \mathrm{~mW} / \mathrm{mm}^{2} \text { and } 25 \% \\
\text { duty cycle }\end{array}$ & $\begin{array}{ll}\text { 1. } & \text { Expected: } 20 \text { hours (non-stop operation) } \\
\text { 2. } & \text { Expected: } 12 \text { hours (non-stop operation) } \\
\text { 3. } & \text { Expected: } 4 \text { hours (non-stop operation) } \\
\end{array}$ \\
\hline
\end{tabular}




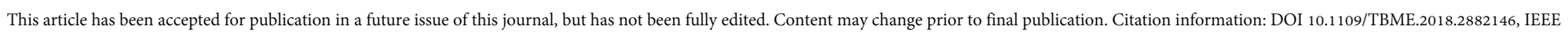

\begin{tabular}{|c|c|c|c|c|c|c|c|}
\hline 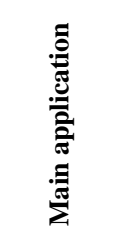 & 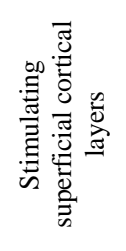 & 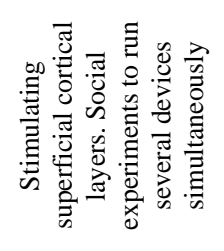 & 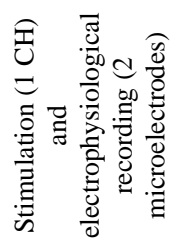 & 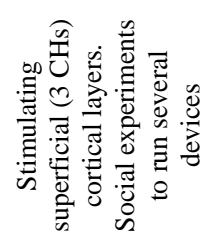 & 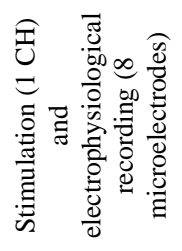 & 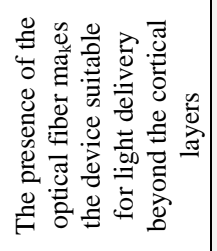 & 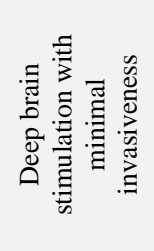 \\
\hline 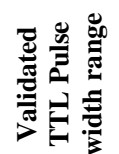 & 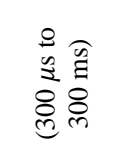 & ' & $\begin{array}{l}0 \\
0 \\
0 \\
0 \\
0 \\
0 \\
0 \\
0\end{array}$ & $\frac{\curvearrowleft}{\star}$ & ' & & $\stackrel{3}{\stackrel{N}{人}}$ \\
\hline 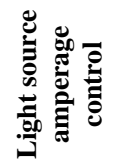 & 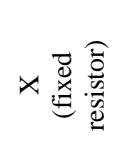 & ' & 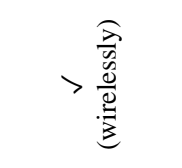 & 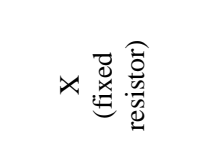 & 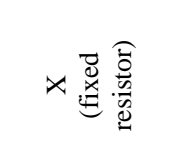 & 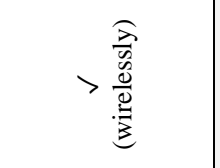 & $>$ 䰹 \\
\hline 递 & 惑 & $\underline{\underline{I}}$ & $\frac{\pi}{\alpha}$ & $\cong$ & $\frac{\pi}{\alpha}$ & $\cong$ & $\cong$ \\
\hline 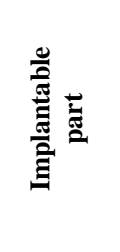 & 国产 & 国 & tr & 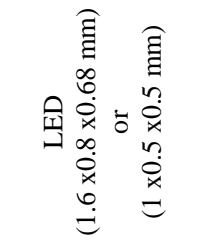 & 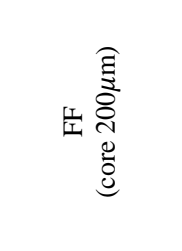 & 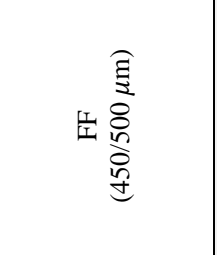 & 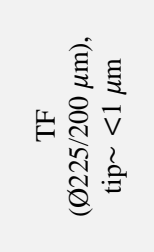 \\
\hline 莺苞 & 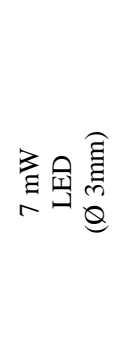 & 团 & 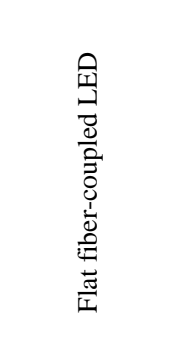 & 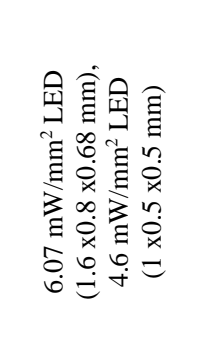 & 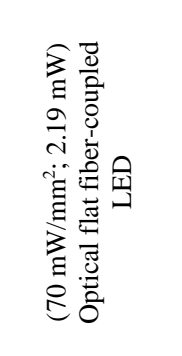 & 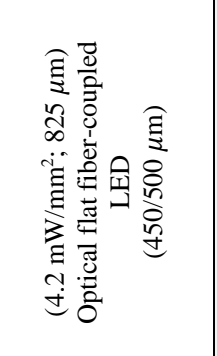 & 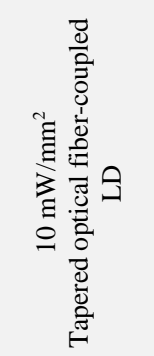 \\
\hline 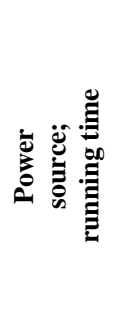 & 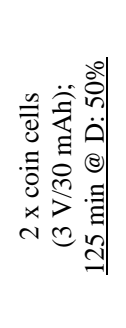 & 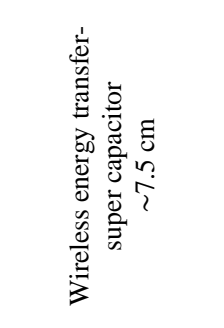 & 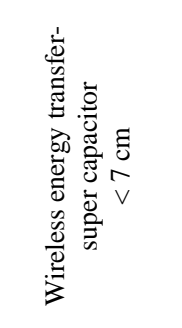 & 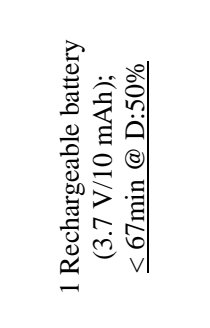 & 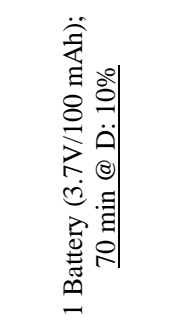 & 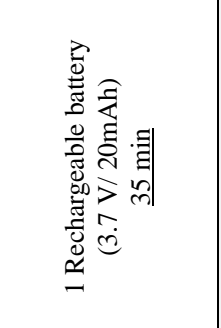 & 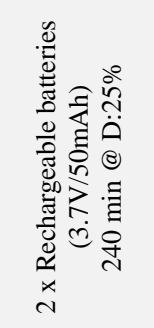 \\
\hline $\begin{array}{l}\vec{E} \\
\frac{0}{000} \\
30\end{array}$ & $\frac{\infty}{m}$ & $\stackrel{\infty}{m}$ & $\begin{array}{l}\stackrel{\infty}{+} \\
\stackrel{+}{r}\end{array}$ & $\begin{array}{l}\infty^{\infty} \\
\stackrel{i}{i}\end{array}$ & $\stackrel{\infty}{\stackrel{0}{+}}$ & $\begin{array}{l}\infty \\
\infty \\
\stackrel{\infty}{i}\end{array}$ & $\begin{array}{l}\infty \\
\infty \\
\infty \\
\dot{r}\end{array}$ \\
\hline 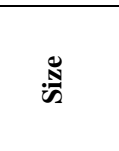 & $\begin{array}{l}\dot{\partial} \\
\dot{x} \\
\dot{x} \\
\text { जे }\end{array}$ & $\begin{array}{l}\tilde{\Xi} \\
\frac{v}{v}\end{array}$ & 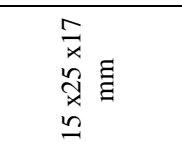 & 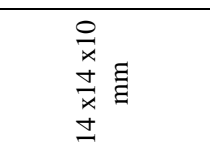 & 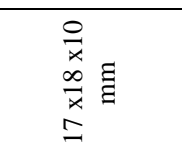 & $\begin{array}{l}\tilde{\vdots} \\
\tilde{n} \\
a \\
o\end{array}$ & $\begin{array}{l}\frac{n}{x} \\
x \\
\frac{m}{x} \\
n \\
n\end{array}$ \\
\hline 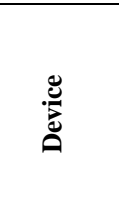 & 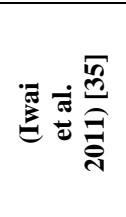 & 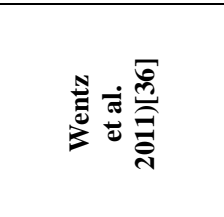 & 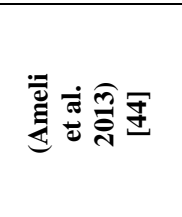 & 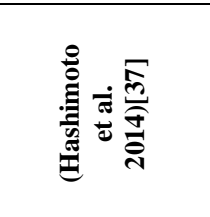 & 总 & 离 & 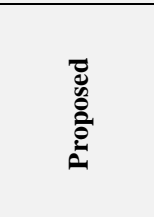 \\
\hline
\end{tabular}


Table IV Comparison of $\mu$ LEDs based wireless optogenetic stimulation devices with our proposed system

\begin{tabular}{|c|c|c|c|c|c|c|c|c|}
\hline & Array of & $\begin{array}{c}\text { Max full } \\
\text { emission } \\
\text { length }\end{array}$ & $\begin{array}{c}\text { Probe } \\
\text { Thickness }\end{array}$ & $\begin{array}{l}\text { Probe } \\
\text { Width }\end{array}$ & $\begin{array}{c}\text { Max optical } \\
\text { power density } \\
\left(\mathbf{m W} / \mathbf{m m}^{2}\right) / \\
\text { Electrical input } \\
\text { power }(\mathrm{mW})\end{array}$ & Weight & $\begin{array}{l}\text { Power } \\
\text { source }\end{array}$ & $\begin{array}{l}\text { Mounting } \\
\text { setup }\end{array}$ \\
\hline $\begin{array}{c}\text { [Kim et al., 2013] } \\
{[15]}\end{array}$ & $\begin{array}{c}4 \mu \text {-ILEDs } \\
(6.45 \mu \mathrm{m} \\
\text { thick, } 50 \times 50 \\
\left.\mu \mathrm{m}^{2}\right)\end{array}$ & $\sim 200 \mu \mathrm{m}$ & $\sim 20 \mu \mathrm{m}$ & $\begin{array}{c}\sim 400 \\
\mu \mathrm{m}\end{array}$ & $40 / 40$ & - & WPT & $\begin{array}{c}\text { Head- } \\
\text { mountable }\end{array}$ \\
\hline $\begin{array}{c}\text { [Jeong et al., 2015] } \\
{[39]}\end{array}$ & $\begin{array}{c}4 \mu \text {-ILEDs } \\
(6.45 \mu \mathrm{m} \\
\text { thick, } 100 \mathrm{x} \\
\left.100 \mu \mathrm{m}^{2}\right)\end{array}$ & $\sim 400 \mu \mathrm{m}$ & $\sim 80 \mu \mathrm{m}$ & $\begin{array}{c}\sim 500 \\
\mu \mathrm{m}\end{array}$ & - & $\sim 1.8 \mathrm{~g}$ & Battery & $\begin{array}{c}\text { Head- } \\
\text { mountable }\end{array}$ \\
\hline $\begin{array}{c}\text { [Rossi et al., 2015] } \\
{[40]}\end{array}$ & $\begin{array}{c}2 \mu \text { LEDs } \\
(140 \mu \mathrm{m} \\
\text { thick, } 240 \mathrm{x} \\
\left.320 \mu \mathrm{m}^{2}\right)\end{array}$ & $\begin{array}{c}\text { Two } \sim 320 \\
\mu \mathrm{m} \\
\text { illuminated } \\
\text { segments with } \\
\text { a pitch of } \sim 4 \\
\mathrm{~mm}\end{array}$ & $\sim 100 \mu \mathrm{m}$ & $\begin{array}{c}\sim 700 \\
\mu \mathrm{m}\end{array}$ & $30 / 32$ & $2.9 \mathrm{~g}$ & Battery & $\begin{array}{c}\text { Head- } \\
\text { mountable }\end{array}$ \\
\hline $\begin{array}{c}\text { [Park et al., 2015] } \\
{[41]}\end{array}$ & $\begin{array}{c}4 \mu \text {-ILEDs } \\
(100 \times 100 \\
\left.\mu \mathrm{m}^{2}\right)\end{array}$ & $\sim 400 \mu \mathrm{m}$ & $\sim 10 \mu \mathrm{m}$ & $\begin{array}{l}\sim 250 \\
\mu \mathrm{m}\end{array}$ & $1 / 2$ & $\sim 70 \mathrm{mg}$ & WPT & $\begin{array}{c}\text { Head- } \\
\text { mountable }\end{array}$ \\
\hline $\begin{array}{c}\text { [Shin et al., 2017] } \\
{[32]}\end{array}$ & $\begin{array}{c}1 \mu \text {-ILEDs } \\
(50 \mu \mathrm{m} \text { thick } \\
270 \times 220 \\
\left.\mu \mathrm{m}^{2}\right)\end{array}$ & $\sim 220 \mu \mathrm{m}$ & $\sim 80-130 \mu \mathrm{m}$ & $\begin{array}{c}\sim 350 \\
\mu \mathrm{m}\end{array}$ & $200 / 62$ & $\sim 30 \mathrm{mg}$ & WPT & $\begin{array}{c}\text { Fully } \\
\text { implantable }\end{array}$ \\
\hline $\begin{array}{c}\text { [Noh et al., 2018] } \\
{[33]}\end{array}$ & $\begin{array}{c}4 \mu \text {-ILEDs } \\
(50 \mu \mathrm{m} \text { thick, } \\
270 \times 220 \\
\left.\mu \mathrm{m}^{2}\right)\end{array}$ & $\sim 880 \mu \mathrm{m}$ & $\sim 80 \mu \mathrm{m}$ & $\begin{array}{l}\sim 500 \\
\mu \mathrm{m}\end{array}$ & $85 / 1000$ & $220 \mathrm{mg}$ & WPT & $\begin{array}{c}\text { Fully } \\
\text { implantable }\end{array}$ \\
\hline Proposed & $\mathrm{TF}$ & $\sim 2 \mathrm{~mm}$ & \multicolumn{2}{|c|}{$\begin{array}{c}\mathrm{TF}, \text { outer diameter }< \\
\emptyset 225 \mu \mathrm{m} \text { to tip }(\sim 500 \\
\mathrm{nm})\end{array}$} & $10 / 270$ & $3.8 \mathrm{~g}$ & Battery & $\begin{array}{c}\text { Head- } \\
\text { mountable }\end{array}$ \\
\hline
\end{tabular}




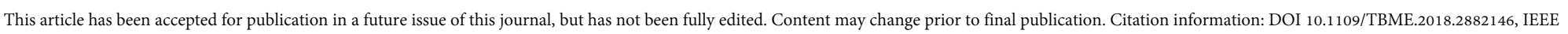

Transactions on Biomedical Engineering

TBME-01112-2018.R1

\begin{tabular}{|c|c|c|c|c|c|c|c|c|c|}
\hline \multirow{4}{*}{ 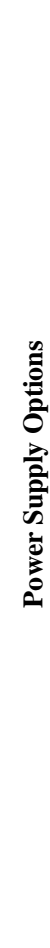 } & \multirow{3}{*}{ 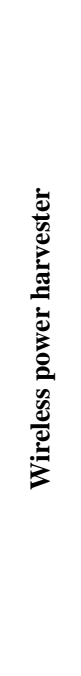 } & 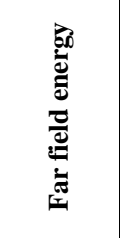 & $\begin{array}{l}\text { N } \\
\stackrel{1}{i} \\
\stackrel{I}{I}\end{array}$ & 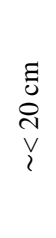 & ' & ' & 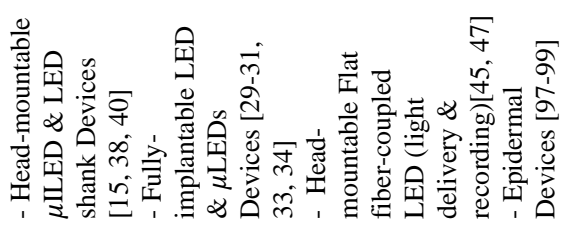 & 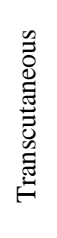 & 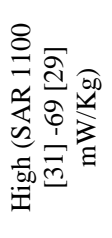 \\
\hline & & 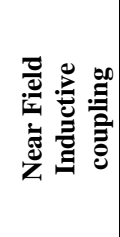 & $\begin{array}{l}N_{1}^{N} \\
\sum_{0} \\
\stackrel{n}{2} \\
\end{array}$ & 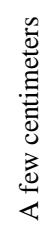 & ' & ' & 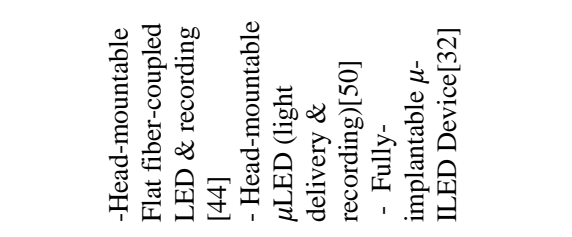 & 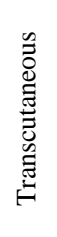 & 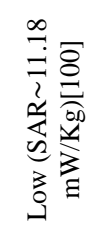 \\
\hline & & 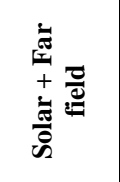 & & 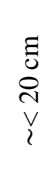 & & ' & 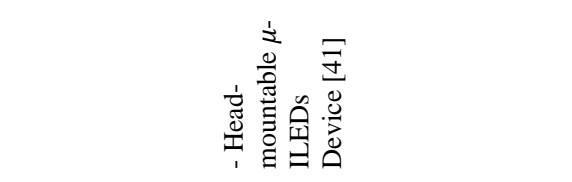 & 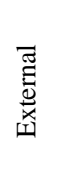 & 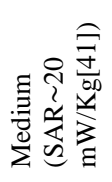 \\
\hline & 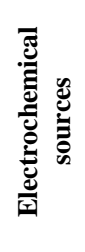 & 离 & & & & ' & 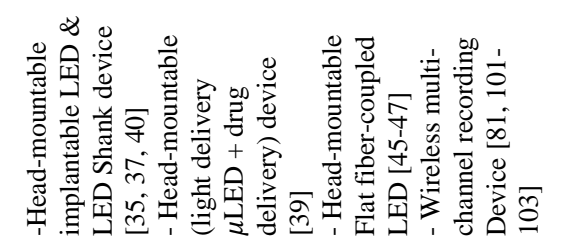 & 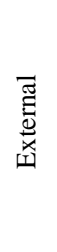 & $\begin{array}{l}\stackrel{0}{0} \\
\stackrel{0}{*}\end{array}$ \\
\hline \multirow{4}{*}{ 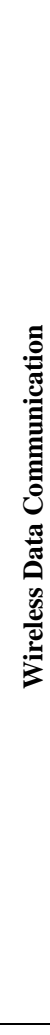 } & \multirow{3}{*}{ 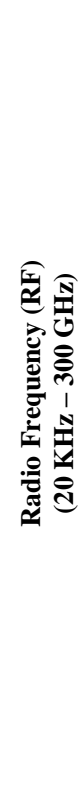 } & 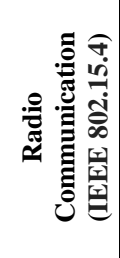 & 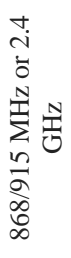 & $\stackrel{\Xi}{\varrho}$ & 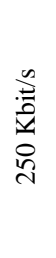 & 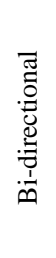 & 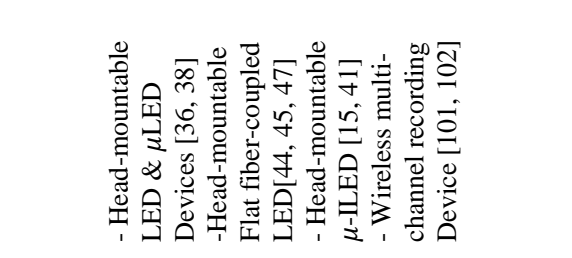 & 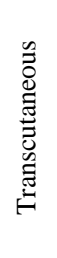 & ' \\
\hline & & 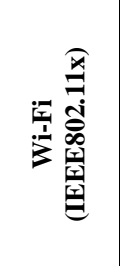 & $\begin{array}{l}\text { N } \\
0 \\
\infty \\
\infty \\
\dot{+} \\
\dot{d}\end{array}$ & $\stackrel{\Xi}{\Xi}$ & $\begin{array}{l}\text { مे } \\
\sum_{0}^{2} \\
\stackrel{0}{1} \\
\stackrel{1}{=}\end{array}$ & 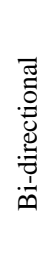 & 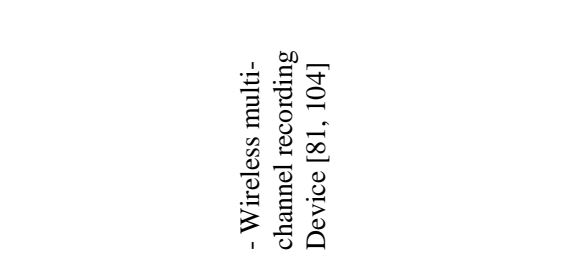 & 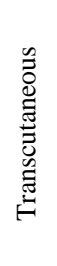 & ' \\
\hline & & 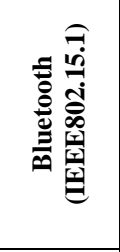 & \begin{tabular}{l} 
Ñ \\
\multirow{J}{*}{} \\
$\stackrel{+}{+}$
\end{tabular} & $\stackrel{\Xi}{\varrho}$ & $\begin{array}{l}\frac{n}{2} \\
\sum^{2} \\
0 \\
0 \\
0\end{array}$ & 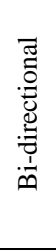 & 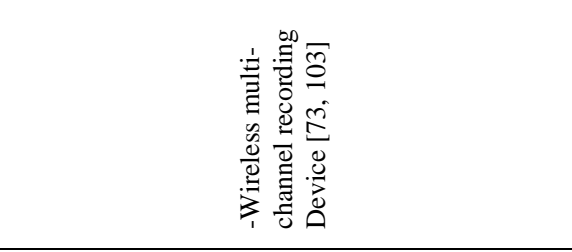 & 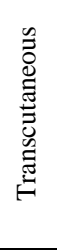 & ' \\
\hline & \multirow{2}{*}{\multicolumn{2}{|c|}{ 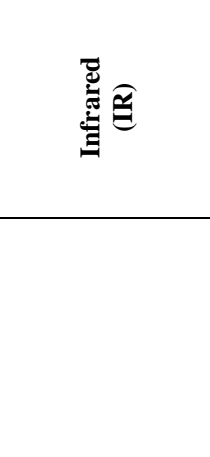 }} & 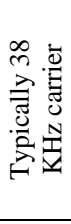 & $\begin{array}{l}E \\
n \\
I\end{array}$ & $\begin{array}{l}\frac{n}{2} \\
\frac{a}{2} \\
\frac{n}{0}\end{array}$ & 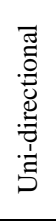 & 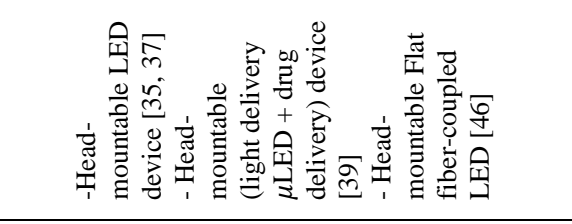 & 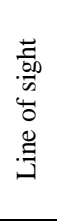 & \\
\hline & & & 总 & 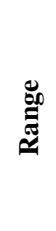 & 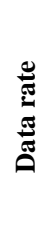 & 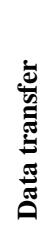 & & 产 & 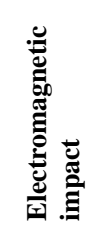 \\
\hline
\end{tabular}

